\title{
Instrumented impact tests on miniaturized Charpy specimens of additively manufactured (AM) \\ Ti-6Al-4V
}

Enrico Lucon

Nik Hrabe

This publication is available free of charge from:

http://dx.doi.org/10.6028/NIST.TN.1936

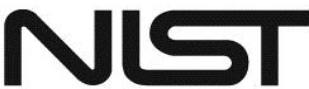

National Institute of Standards and Technology U.S. Department of Commerce 


\title{
Instrumented impact tests on miniaturized Charpy specimens of additively manufactured (AM) \\ Ti6Al4V
}

\author{
Enrico Lucon \\ Nik Hrabe \\ Applied Chemicals and Materials Division \\ Material Measurement Laboratory
}

This publication is available free of charge from:

http://dx.doi.org/10.6028/NIST.TN.1936

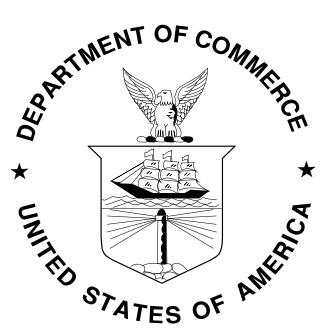

U.S. Department of Commerce Penny Pritzker, Secretary

National Institute of Standards and Technology Willie May, Under Secretary of Commerce for Standards and Technology and Director 
Certain commercial entities, equipment, or materials may be identified in this document in order to describe an experimental procedure or concept adequately. Such identification is not intended to imply recommendation or endorsement by the National Institute of Standards and Technology, nor is it intended to imply that the entities, materials, or equipment are necessarily the best available for the purpose.

National Institute of Standards and Technology Technical Note 1936 Natl. Inst. Stand. Technol. Tech. Note 1936, 36 pages (September 2016) CODEN: NTNOEF

This publication is available free of charge from: http://dx.doi.org/10.6028/NIST.TN.1936 


\begin{abstract}
An investigation on the impact toughness properties of wrought and additively-manufactured (AM) Ti-6Al-4V was conducted at NIST Boulder, by means of instrumented impact tests on miniaturized Charpy specimens. Full transition curves for absorbed energy and lateral expansion were obtained by performing tests in the temperature range between $-196{ }^{\circ} \mathrm{C}$ and $700{ }^{\circ} \mathrm{C}$. The effect of various parameters was investigated for AM specimens, namely specimen orientation, Hot Isostatic Pressing (HIPping), and notch configuration (printed or machined). Our results indicate that AM specimens exhibit equivalent or better impact toughness than wrought material after HIPping, and that the material is more resistant to cracks growing in the plane perpendicular to the build direction than in the plane containing the build direction. HIPping has a significantly beneficial effect for the AM material, while no effect of notch configuration was observed from the results obtained. Characteristic instrumented forces allow a qualitative assessment of dynamic tensile properties, which appear to be similar for wrought and AM Ti-6Al-4V.
\end{abstract}

\title{
Keywords
}

Additive manufacturing; Hot Isostatic Pressing; impact toughness; instrumented Charpy tests; miniaturized Charpy specimens; Ti-6Al-4V. 


\section{Table of Contents}

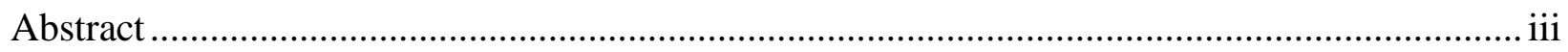

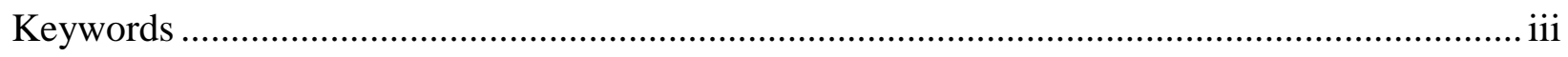

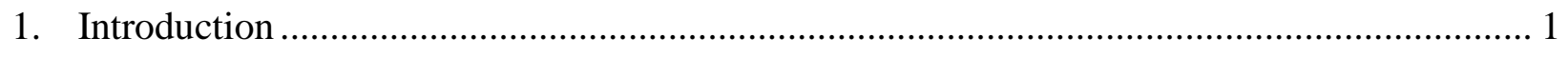

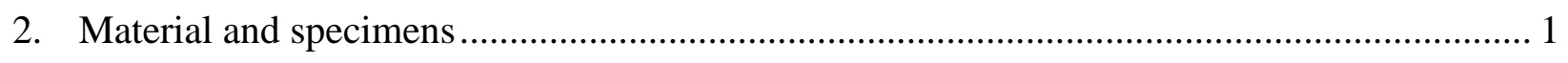

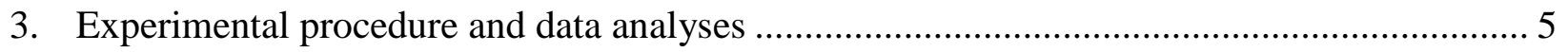

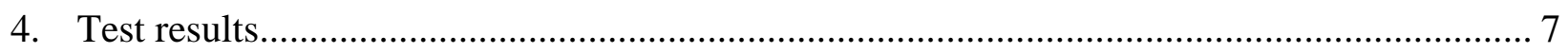

4.1. Baseline 1 and Baseline 2 specimens ............................................................ 7

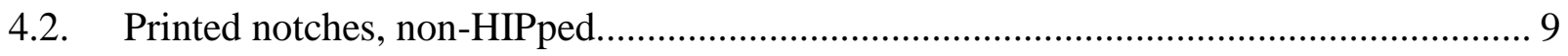

4.3. Printed notches, HIPped .................................................................................. 11

4.4. Machined notches, non-HIPped ......................................................................... 14

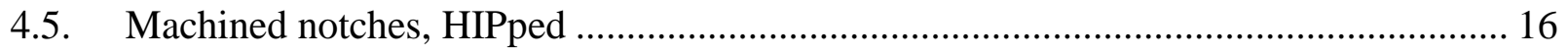

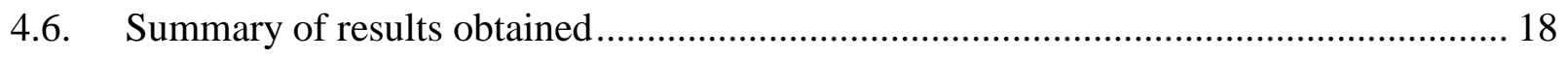

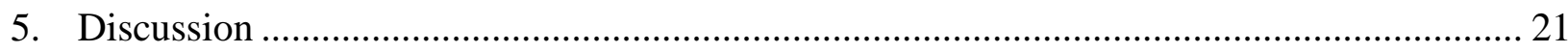

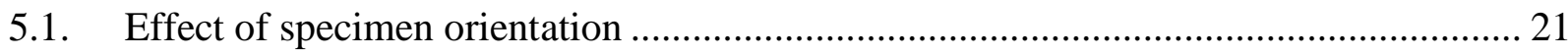

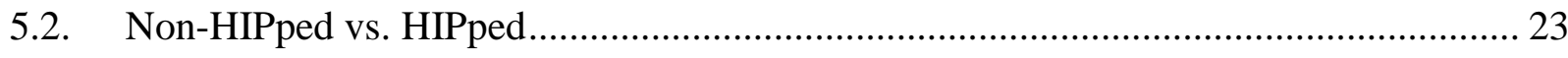

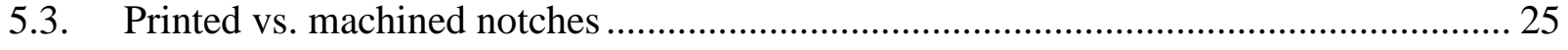

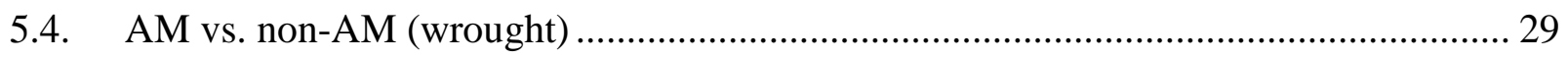

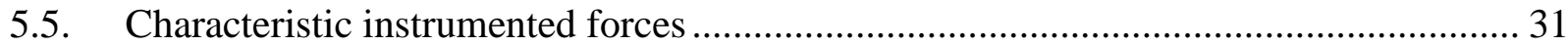

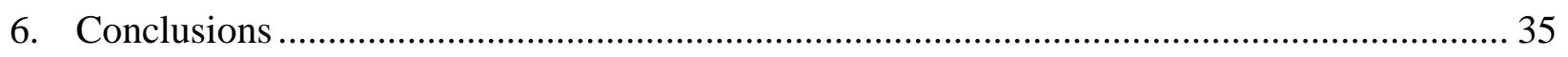

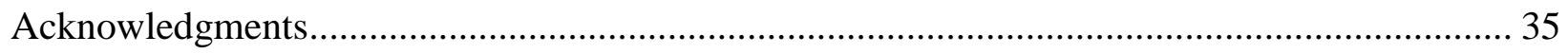

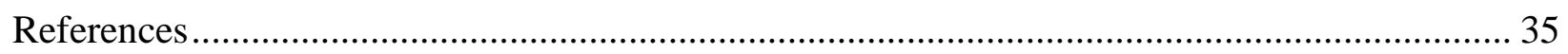




\section{Introduction}

Titanium alloys are known to have high mechanical resistance and toughness, even at extreme temperatures. They are light in weight, have excellent corrosion resistance and the ability to withstand extreme temperatures. However, the high cost of both raw materials and processing limit their use to military applications, aircraft, spacecraft, medical devices, highly stressed components such as connecting rods on expensive sports cars, and some premium sports equipment and consumer electronics.

Although commercially pure titanium has acceptable mechanical properties and has been used for orthopedic and dental implants, for most applications titanium is alloyed with aluminum and vanadium. These alloys have a solid solubility which varies dramatically with temperature, allowing it to undergo precipitation strengthening. This heat treatment process is carried out after the alloy has been worked into its final shape but before it is put to use, allowing much easier fabrication of a high-strength product.

Among Ti alloys, Ti-6Al-4V (also known as Ti 6-4) is by far most commonly used, accounting for more than $50 \%$ of the total Ti usage [1]. It is an $\alpha+\beta$ alloy that is heat treatable to achieve moderate increases in strength, and is recommended for use at service temperatures up to approximately $350{ }^{\circ} \mathrm{C}$ [1]. Its applications include aircraft turbine engine components, aircraft structural components, aerospace fasteners, high-performance automotive parts, marine applications, medical devices, and sports equipment [1]. Toughness is an important consideration in the design of all these structures.

In this investigation, we characterized the impact toughness properties of additively-manufactured (AM) Ti 6-4 by means of instrumented Charpy tests on miniaturized specimens. Tests were performed at temperatures ranging from $-196{ }^{\circ} \mathrm{C}$ to $700{ }^{\circ} \mathrm{C}$, in order to obtain full transition curves and calculate parameters such as ductile-to-brittle transition temperatures (DBTTs) and the upper-shelf energy (USE).

AM Charpy specimens were manufactured in two orientations (horizontal and vertical) and in two machining conditions (as-built notches and machined notches), and in HIPped ${ }^{1}$ and non-HIPped state. For benchmarking purposes, these eight conditions were compared with specimens extracted from two rods of non-AM Ti 6-4 purchased from two different suppliers.

\section{Material and specimens}

As previously mentioned, both non-AM ("baseline”) and AM Ti-6Al-4V specimens were tested. The ten material conditions that were characterized were the following:

\footnotetext{
${ }^{1}$ HIP $=$ Hot Isostatic Pressing (a manufacturing process, by which a component is subjected to both elevated temperature and isostatic gas pressure in a high pressure containment vessel, in order to improve the material's mechanical properties and workability).
} 
a) Baseline 1 [B1]: non-AM specimens extracted from a rod of wrought Ti-6Al-4V, purchased from supplier 1 . The samples were machined with the long axis parallel to the rod axis, and the notch in the radial direction.

b) Baseline 2 [B2]: non-AM specimens extracted from a second rod of wrought Ti-6Al-4V, purchased from supplier 2. The samples were machined with the long axis parallel to the rod axis, and the notch in the radial direction.

c) Printed notches/horizontal direction/non-HIPped [PHnH]: specimens prepared by additive manufacturing in the horizontal direction (perpendicular to the build direction) and non-HIPped.

d) Printed notches/vertical direction/non-HIPped [PVnH]: specimens prepared by additive manufacturing in the vertical direction (parallel to the build direction) and non-HIPped.

e) Printed notches/horizontal direction/HIPped [PHH]: specimens prepared by additive manufacturing in the horizontal direction (perpendicular to the build direction) and HIPped.

f) Printed notches/vertical direction/HIPped [PVH]: specimens prepared by additive manufacturing in the vertical direction (parallel to the build direction) and HIPped.

g) Machined notches/horizontal direction/non-HIPped [MHnH]: specimens machined from an additively-manufactured block in the horizontal direction (perpendicular to the build direction) and non-HIPped.

h) Machined notches/vertical direction/non-HIPped [MVnH]: specimens machined from an additively-manufactured block in the vertical direction (parallel to the build direction) and non-HIPped.

i) Machined notches/horizontal direction/HIPped [MHH]: specimens machined from an additively-manufactured block in the horizontal direction (perpendicular to the build direction) and HIPped.

j) Machined notches/vertical direction/HIPped [MVH]: specimens machined from an additively-manufactured block in the vertical direction (parallel to the build direction) and HIPped.

For AM specimens, the sketch in Figure 1 illustrates the meaning of horizontal and vertical direction, with respect to the build direction. Note that specimen orientation can also be designated by the use of three letters, where the first letter is the direction of the specimen main axis, the second the direction parallel to the notch, and the third the direction of crack propagation. In Figure $1, \mathrm{Z}$ corresponds to the build direction.

The miniaturized Charpy specimens used for this investigation were of the RHS (Reduced Half-Size) type, which is included in the ASTM E2248-15 standard ${ }^{2}$. Its nominal dimensions are illustrated in Figure 2. Note that specimens with printed notches had smaller dimensions than those in Figure 2, since their surfaces were machined to avoid excessive friction between Charpy

\footnotetext{
2 ASTM E2248-15, “Standard Test Method for Impact Testing of Miniaturized Charpy V-Notch Specimens,” ASTM Book of Standards, Vol. 03.01, ASTM International, West Conshohocken, PA, 2015.
} 
machine and the rough surfaces resulting from AM (3-D printing). All specimen dimensions were measured before testing, including notch depth by optical profilometry.

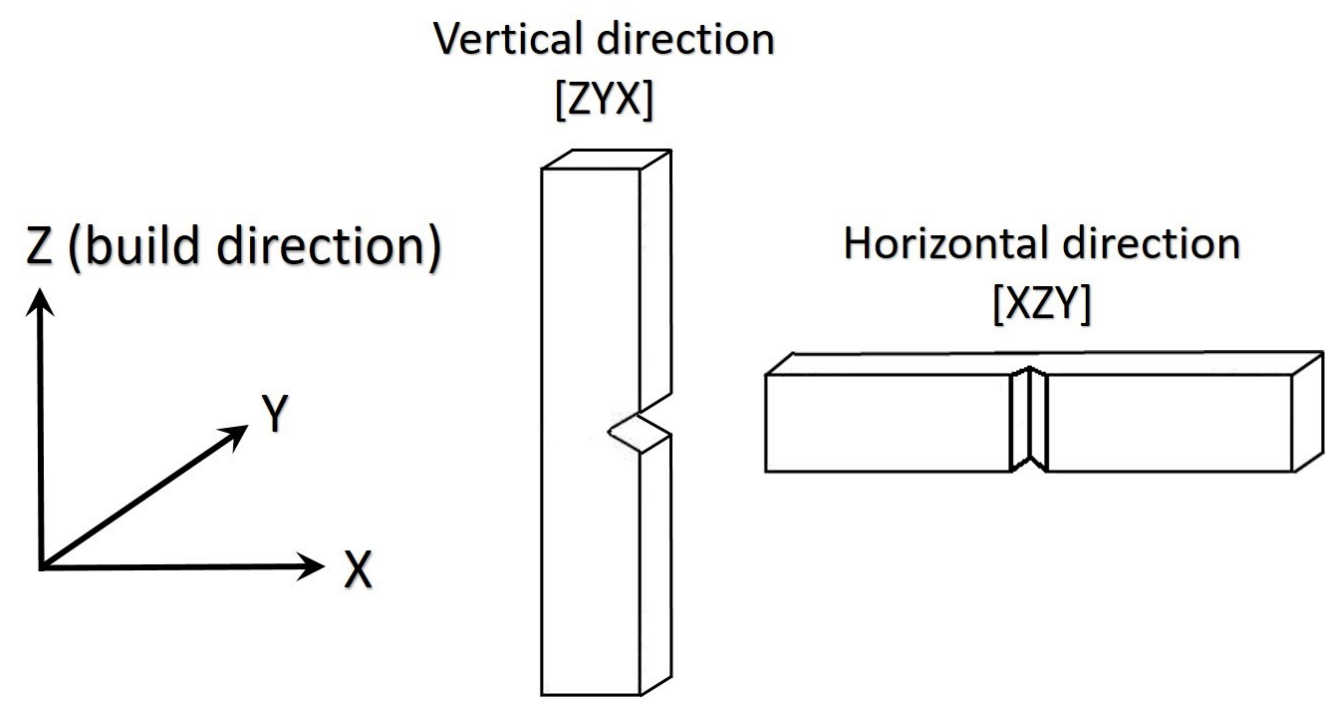

Figure 1 - Illustration of building directions for miniaturized AM Charpy specimens.
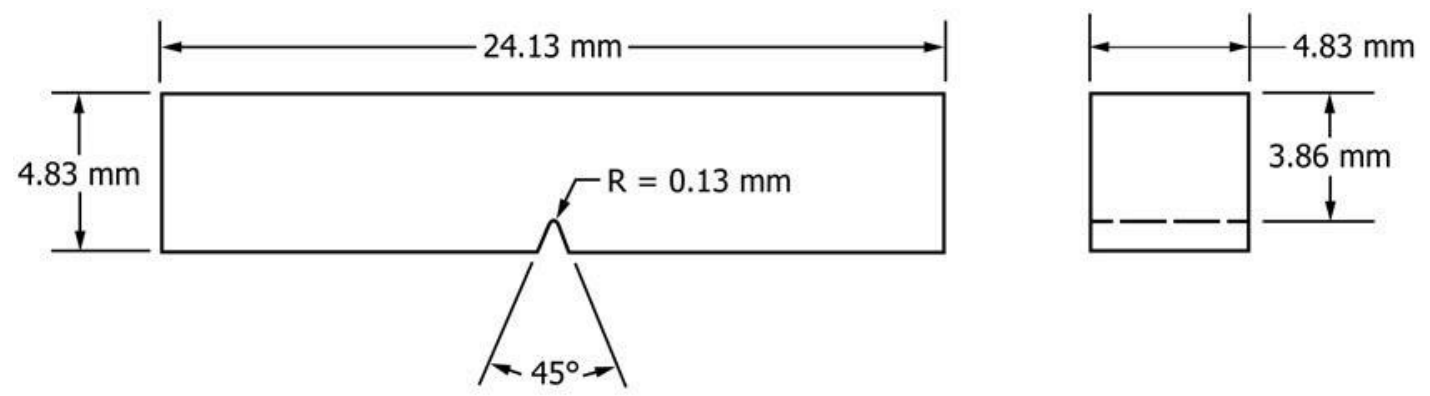

Figure 2 - Nominal dimensions for RHS Charpy specimens.

Additive manufacturing was performed with the following parameters: accelerating voltage $60 \mathrm{kV}$, layer thickness $50 \mu \mathrm{m}$, speed factor 35. This is the standard build theme for Ti-6Al-4V. Gas-atomized powder with average particle diameter $70 \mu \mathrm{m}$ (diameter range $40 \mu \mathrm{m}-$ $100 \mu \mathrm{m})$ was used.

The conditions for Hot Isostatic Pressing (HIPping) were: 2 hours at $900{ }^{\circ} \mathrm{C}$, argon atmosphere, heating and cooling rates $12{ }^{\circ} \mathrm{C} / \mathrm{min}$, pressure $100 \mathrm{MPa}$. This can be considered a standard HIP heat treatment for Ti-6Al-4V.

The chemical composition of the characterized materials is provided in Table 1, with reference to the two non-AM conditions (B1 and B2), the AM specimens in non-HIPped condition $(\mathrm{AMnH})$, and the AM specimens in HIPped condition $(\mathrm{AMH})^{3}$.

\footnotetext{
${ }^{3}$ On page 2, AMnH corresponds to items c, d, g, and h, while AMH corresponds items e, f, i and j.
} 
Table 1 - Chemical composition of characterized materials (weight \%).

\begin{tabular}{|ccccccccc|}
\hline Condition & Al & $\mathbf{C}$ & $\mathbf{F e}$ & $\mathbf{H}$ & $\mathbf{N}$ & $\mathbf{O}$ & $\mathbf{V}$ & $\mathbf{T i}$ \\
\hline $\mathbf{B 1}$ & 6.58 & 0.02 & 0.250 & 0.003 & 0.010 & 0.180 & 4.3 & Bal. \\
\hline B2 $^{4}$ & 6.39 & 0.03 & 0.165 & 0.003 & 0.025 & 0.175 & 4.0 & Bal. \\
\hline AMnH & 5.89 & 0.01 & 0.160 & 0.001 & 0.020 & 0.140 & 4.4 & Bal. \\
\hline AMH & 5.82 & 0.01 & 0.170 & 0.001 & 0.020 & 0.140 & 4.3 & Bal. \\
\hline
\end{tabular}

The additively-manufactured specimens were split between printed and machined notches. Samples from the former group were manufactured by the AM process and subsequently milled in order to reduce friction between specimen and machine (anvils, supports, striker) during the impact tests. However, the lateral surfaces and root of the notch were in as-manufactured (asprinted) condition, and exhibited significant ruggedness and asperities as illustrated in Figure 3.

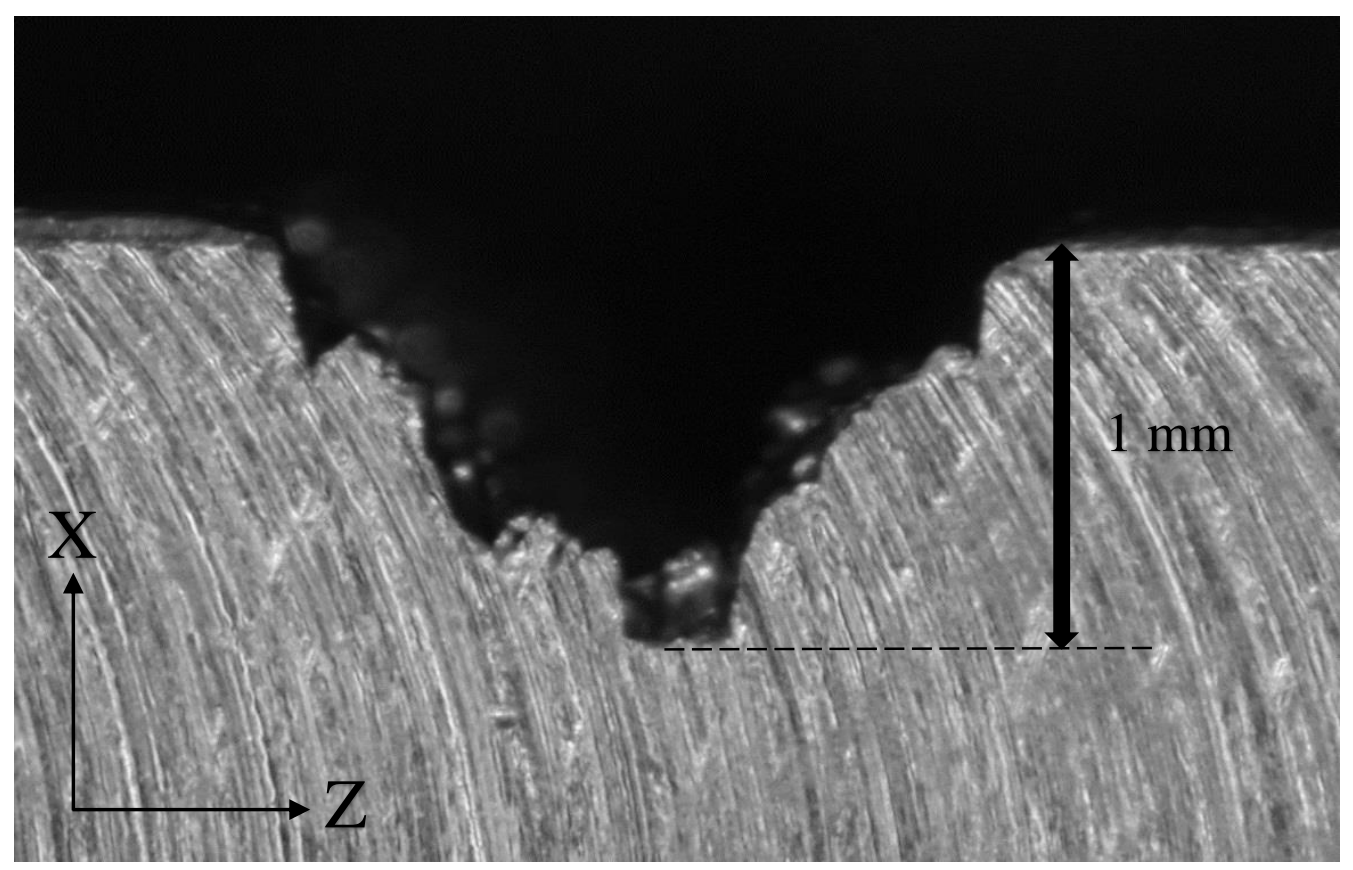

Figure 3 - Stereo-micrograph of the printed notch of a miniaturized Charpy specimen (vertical direction).

Conversely, specimens from the machined-notch group were manufactured by a professional machine shop from a block of AM Ti-6Al-4V, and notches had therefore much flatter and smoother surfaces and roots.

\footnotetext{
${ }^{4}$ Average between top and bottom of the rod.
} 


\section{Experimental procedure and data analyses}

Instrumented impact tests were performed on a small-scale Charpy machine equipped with an instrumented striker. The machine has a capacity (potential energy) of $50.8 \mathrm{~J}$ and an impact velocity of $3.5 \mathrm{~m} / \mathrm{s}$. In accordance with ASTM E2248, the radius of the striking edge is $3.86 \mathrm{~mm}$ (nominal $4 \mathrm{~mm}$ striker).

Tests were performed at temperatures ranging from $-196{ }^{\circ} \mathrm{C}$ to $700{ }^{\circ} \mathrm{C}$. For test temperatures below room temperature $\left(21^{\circ} \mathrm{C}\right)$, specimens were first immersed in liquid nitrogen and then transferred to the impact position in the shortest possible time by means of suitable tongs. Each specimen was instrumented with a thermocouple, so that its actual temperature at the time of impact could be recorded. For tests above $21^{\circ} \mathrm{C}$, the specimen temperature was monitored by a non-contact infrared temperature sensor. For tests up to $200^{\circ} \mathrm{C}$, specimens were heated by means of a heat gun; above $200{ }^{\circ} \mathrm{C}$, a small furnace was used. In all cases, specimens were overheated by $100-150{ }^{\circ} \mathrm{C}$ to account for heat loss during transfer. The overall precision in test temperature measurement can be estimated in the order of $\pm 3{ }^{\circ} \mathrm{C}$.

For every specimen tested, absorbed energy was measured by the encoder of the Charpy machine. Lateral expansion (i.e., increase of specimen thickness caused by plastic deformation) was measured on the broken samples by means of a caliper.

Since the specimen groups corresponding to the various conditions had slightly different cross-section dimensions, both absorbed energy and lateral expansion were normalized for comparison purposes according to the following procedure:

- absorbed energy $(K V)$ was normalized by the factor $B d^{2}$, where $B$ is specimen thickness and $d$ is the ligament size ${ }^{5}$, i.e., $K V_{\text {norm }}=K V / B d^{2}$;

- lateral expansion $(L E)$ was normalized by the initial specimen thickness, i.e., $L E_{\mathrm{norm}}=$ $L E / B$.

Values of normalized energy (in $\mathrm{N} / \mathrm{mm}$ ) and lateral expansion (in \%) were plotted and fitted as a function of test temperature by means of the following analytical model (TANH hyperbolic tangent) [5]:

$$
P(T)=A+B \cdot \tanh \left(\frac{T-D B T T}{C}\right)
$$

where: $\quad P(T)$ is the dependent variable (normalized absorbed energy or lateral expansion);

$T$ is the independent variable (test temperature);

$D B T T$ is the ductile-to-brittle transition temperature (temperature corresponding to the inflection point of the curve);

$A, B$, and $C$ are additional regression coefficients ${ }^{6}$.

\footnotetext{
${ }^{5}$ In previous investigations [2-4], the normalization factor $B d^{2}$ was found to be the most effective for comparing absorbed energy values obtained from different Charpy specimen types.

${ }^{6} A+B$ corresponds to the upper asymptotic value (upper shelf plateau). $C$ is the half-width of the transition region (temperature interval between lower and upper shelf).
} 
In order to investigate a temperature range as wide as possible and sufficiently characterize the transitional behavior of every condition, only one specimen was tested at each temperature. Therefore, when comparing experimental results and transition curves, no statement can be formulated about the uncertainty of the calculated parameters or the statistical confidence of the comparisons between material conditions.

From the analysis of the instrumented Charpy test records, several characteristic force values can be identified. Two of them, $F_{g y}$ (force at general yield) and $F_{m}$ (maximum force), can be analytically related for full-size Charpy specimens to the dynamic yield strength [6] and the dynamic ultimate tensile strength [7] respectively. For miniaturized Charpy specimens, no equivalent analytical or empirical relationship has been proposed yet, but it is reasonable to assume that $F_{g y}$ and $F_{m}$ remain proportional to the respective dynamic tensile properties. 


\section{Test results}

\subsection{Baseline 1 and Baseline 2 specimens}

For the B1 condition, 12 specimens were tested between $-160{ }^{\circ} \mathrm{C}$ and $700{ }^{\circ} \mathrm{C}$. For B2, 15 specimens were tested at three temperatures $\left(-50{ }^{\circ} \mathrm{C}, 21{ }^{\circ} \mathrm{C}\right.$, and $100{ }^{\circ} \mathrm{C}, 5$ specimens per temperature). Test results are shown in Table 2, Figure 4 (normalized absorbed energy) and Figure 5 (normalized lateral expansion). On account of the small temperature range, B2 results were fitted by a $2^{\text {nd }}$-order polynomial.

Table 2 - Test results for the B1 and B2 data sets.

\begin{tabular}{|cccccc|}
\hline $\begin{array}{c}\text { Material } \\
\text { condition }\end{array}$ & $\begin{array}{c}\mathbf{T} \\
\left({ }^{\mathbf{C}} \mathbf{C}\right)\end{array}$ & $\begin{array}{c}\boldsymbol{K} \boldsymbol{V} \\
(\mathbf{J})\end{array}$ & $\begin{array}{c}\boldsymbol{K} \boldsymbol{V}_{\text {norm }} \\
(\mathbf{N} / \mathbf{m m})\end{array}$ & $\begin{array}{c}\boldsymbol{L} \boldsymbol{E} \\
(\mathbf{m m})\end{array}$ & $\begin{array}{c}\boldsymbol{L} \boldsymbol{E}_{\text {norm }} \\
(\boldsymbol{\%})\end{array}$ \\
\hline & -160 & 3.33 & 43.1 & 0.11 & 2.23 \\
& -101 & 3.23 & 41.3 & 0.16 & 3.23 \\
& -50 & 4.30 & 55.7 & 0.16 & 3.23 \\
& 21 & 4.99 & 63.7 & 0.18 & 3.62 \\
& 100 & 6.59 & 84.0 & 0.33 & 6.63 \\
$\mathbf{B 1}$ & 180 & 9.28 & 118.5 & 0.45 & 9.05 \\
& 232 & 14.83 & 188.9 & 0.72 & 14.46 \\
& 280 & 16.64 & 213.9 & 0.85 & 17.14 \\
& 395 & 18.17 & 230.8 & 0.85 & 17.10 \\
& 495 & 23.17 & 298.5 & 1.10 & 22.22 \\
& 595 & 22.61 & 287.5 & 1.04 & 20.84 \\
& 700 & $31.80^{7}$ & 409.7 & 1.04 & 21.01 \\
\hline \multirow{6}{*}{ B2 } & -51 & $\mathrm{~N} / \mathrm{A}$ & $\mathrm{N} / \mathrm{A}$ & 0.09 & 1.84 \\
& -52 & 4.07 & 55.2 & 0.07 & 1.44 \\
& -49 & 4.32 & 58.2 & 0.09 & 1.84 \\
& -50 & 4.46 & 60.0 & 0.10 & 2.04 \\
& -50 & 4.22 & 56.5 & 0.12 & 2.44 \\
& 21 & 5.05 & 68.6 & 0.13 & 2.66 \\
& 21 & 5.03 & 68.4 & 0.12 & 2.44 \\
& 21 & $\mathrm{~N} / \mathrm{A}$ & $\mathrm{N} / \mathrm{A}$ & 0.13 & 2.65 \\
& 21 & 5.05 & 67.9 & 0.17 & 3.48 \\
& 21 & 4.76 & 64.0 & 0.16 & 3.27 \\
& 100 & 6.00 & 80.8 & 0.27 & 5.53 \\
& 100 & 5.92 & 78.7 & 0.23 & 4.72 \\
& 100 & 6.42 & 85.7 & 0.21 & 4.29 \\
& 100 & 7.11 & 94.8 & 0.26 & 5.33 \\
& 100 & 6.37 & 84.8 & 0.22 & 4.50 \\
\hline
\end{tabular}

${ }^{7}$ Specimen jamming suspected. 


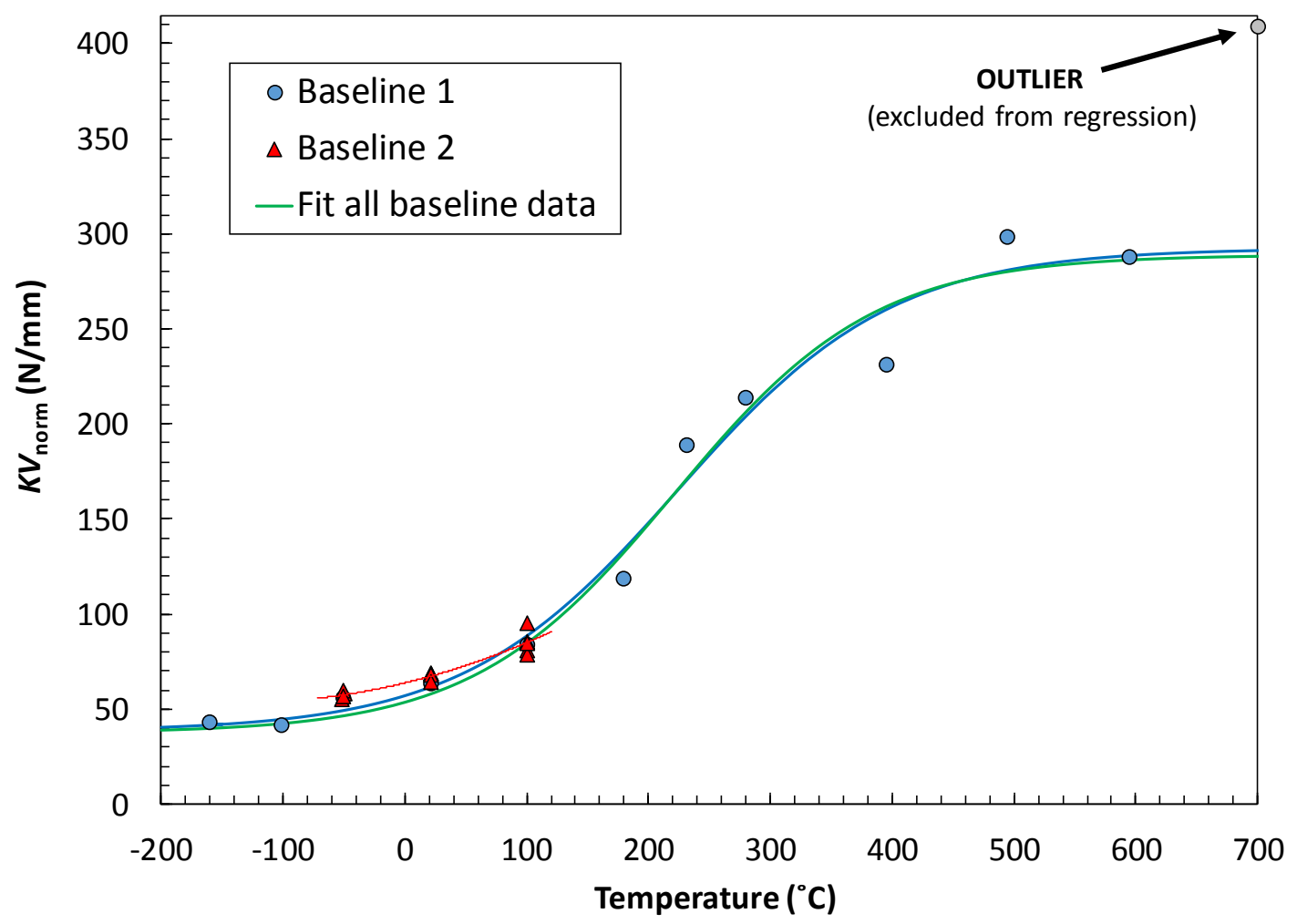

Figure 4 - Normalized absorbed energy for the two baseline conditions.

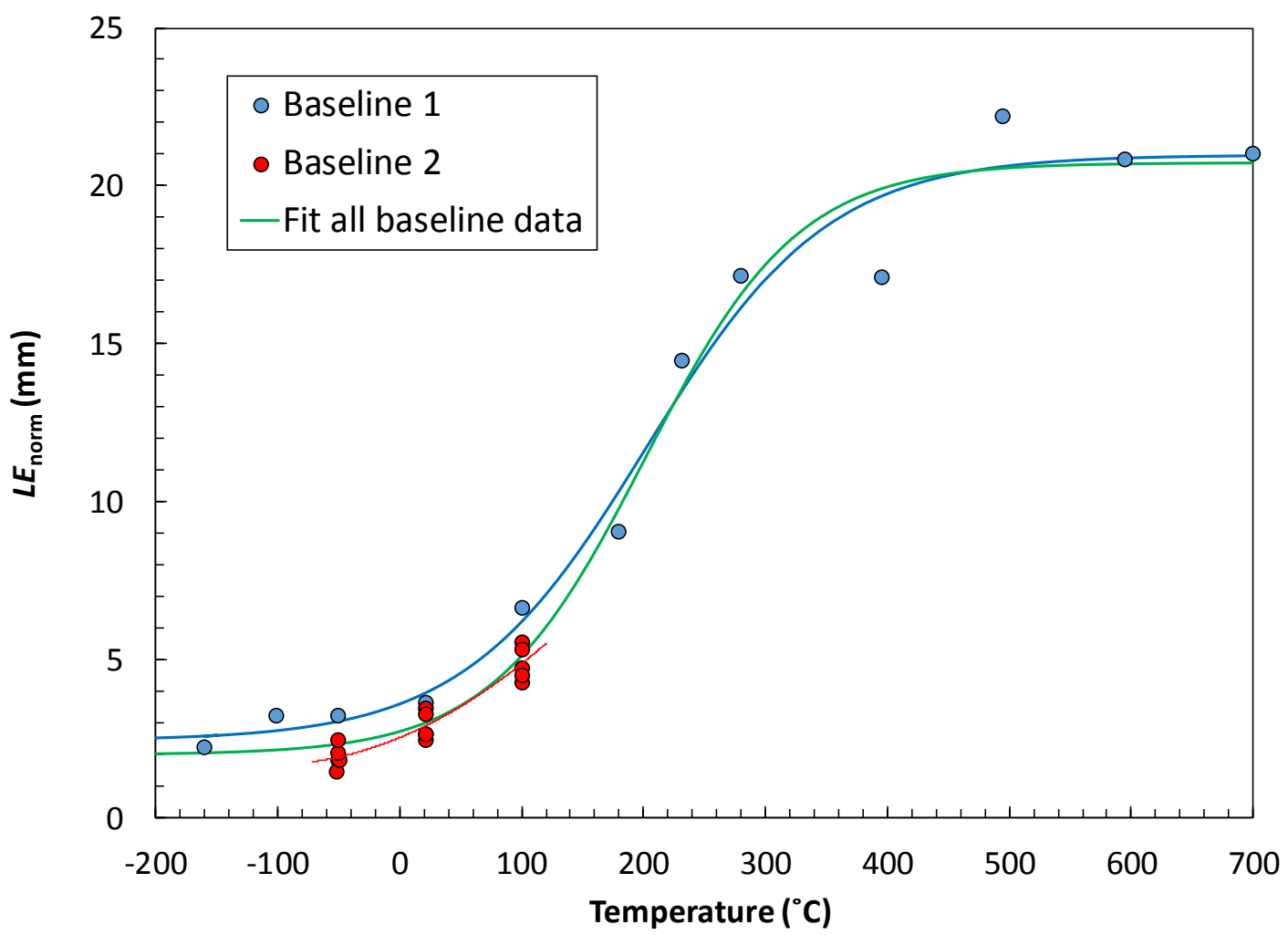

Figure 5 - Normalized lateral expansion for the two baseline conditions. 
The difference between the results obtained from the two baseline conditions (particularly in terms of normalized energy) was considered small, and therefore data from the two baseline conditions were combined (B1-B2, green regression curves in Figure 4 and Figure 5) for comparison with the AM conditions.

The value of absorbed energy for the $\mathrm{B} 1$ specimen tested at $700^{\circ} \mathrm{C}$ appears to be an outlier, and could have been caused by specimen jamming (the value of lateral expansion for that specimen was normal). This data point was not used for the obtainment of the $K V_{\text {norm }}$ transition curve.

The analysis results for B1 and the combined data set (B1-B2) are summarized in Table 3. The most significant results are highlighted in bold red.

\section{Table 3 -Analysis results for the baseline data sets. NOTE: $R^{2}$ is the coefficient of determination of the fit, and indicates the proportion of the variance in the dependent variable that is predictable from the independent variable.}

\begin{tabular}{|cccc|}
\hline Data set & Parameter & $\boldsymbol{K} \boldsymbol{V}_{\text {norm }}$ & $\boldsymbol{L} \boldsymbol{E}_{\text {norm }}$ \\
\hline & $A$ & $165.4 \mathrm{~N} / \mathrm{mm}$ & $11.7 \%$ \\
& $B$ & $126.6 \mathrm{~N} / \mathrm{mm}$ & $9.3 \%$ \\
B1 & $C$ & $177.1^{\circ} \mathrm{C}$ & $149.3^{\circ} \mathrm{C}$ \\
& $D B T T$ & $\mathbf{2 2 4 . 0}{ }^{\circ} \mathrm{C}$ & $\mathbf{2 0 1 . 8}{ }^{\circ} \mathrm{C}$ \\
& $\boldsymbol{U S E} E$ & $\mathbf{2 9 2 . 0 ~ N / m m}$ & - \\
& $R^{2}$ & 0.9505 & 0.9117 \\
\hline & $A$ & $163.0 \mathrm{~N} / \mathrm{mm}$ & $11.4 \%$ \\
& $B$ & $126.0 \mathrm{~N} / \mathrm{mm}$ & $9.4 \%$ \\
B1-B2 & $C$ & $165.1^{\circ} \mathrm{C}$ & $125.8^{\circ} \mathrm{C}$ \\
& $D B T T$ & $\mathbf{2 2 0 . 7}{ }^{\circ} \mathrm{C}$ & $\mathbf{2 0 0 . 8}{ }^{\circ} \mathrm{C}$ \\
& $\boldsymbol{U S E}$ & $\mathbf{2 8 8 . 9 ~ N / m m}$ & - \\
& $R^{2}$ & 0.9821 & 0.9217 \\
\hline
\end{tabular}

\subsection{Printed notches, non-HIPped}

For the printed notch/non-HIPped condition, 20 specimens were tested between $-195{ }^{\circ} \mathrm{C}$ and $605{ }^{\circ} \mathrm{C}, 10$ in horizontal direction $(\mathrm{PHnH})$ and 10 in vertical direction $(\mathrm{PVnH})$. Test results are shown in Table 4, Figure 6 (normalized absorbed energy), and Figure 7 (normalized lateral expansion).

The results obtained show that the vertical direction has better impact toughness (lower DBTTs, higher upper shelf energies) than the horizontal direction. We also note that more scatter is associated with the vertical direction, particularly in the upper transition and upper shelf regions.

The analysis results for $\mathrm{PHnH}$ and $\mathrm{PVnH}$ are summarized in Table 5. The most significant results are highlighted in bold red. 
Table 4 - Test results for the printed notch/non-HIPped specimens.

\begin{tabular}{ccccccc}
$\begin{array}{c}\text { Material } \\
\text { condition }\end{array}$ & Direction & $\begin{array}{c}\mathbf{T} \\
\left({ }^{\circ} \mathbf{C}\right)\end{array}$ & $\begin{array}{c}\boldsymbol{K} \boldsymbol{V} \\
(\mathbf{J})\end{array}$ & $\begin{array}{c}\boldsymbol{K} \boldsymbol{V}_{\text {norm }} \\
(\mathbf{N} / \mathbf{m m})\end{array}$ & $\begin{array}{c}\boldsymbol{L} \boldsymbol{E} \\
(\mathbf{m m})\end{array}$ & $\begin{array}{c}\boldsymbol{L} \boldsymbol{E}_{\text {norm }} \\
(\mathbf{\%})\end{array}$ \\
\hline \multirow{6}{*}{ PHnH } & & -195 & 2.69 & 41.0 & 0.03 & 0.65 \\
& & -97 & 3.13 & 47.4 & 0.03 & 0.66 \\
& & -50 & 2.99 & 46.7 & 0.03 & 0.66 \\
& & 22 & 3.79 & 58.2 & 0.09 & 1.96 \\
& & 100 & 5.14 & 77.9 & 0.13 & 2.80 \\
& & 200 & N/A & N/A & 0.31 & 6.77 \\
& & 201 & 7.34 & 111.9 & 0.25 & 5.46 \\
& & 435 & 10.05 & 137.3 & 0.42 & 9.15 \\
PVnH & & 595 & 11.30 & 176.5 & 0.46 & 10.09 \\
& & -174 & 1.58 & 24.1 & 0.58 & 12.47 \\
\hline & & -102 & 2.45 & 39.2 & 0.02 & 0.43 \\
& & -51 & 3.58 & 53.4 & 0.06 & 1.29 \\
& & 22 & 4.96 & 77.8 & 0.17 & 3.73 \\
& & 95 & 7.92 & 122.3 & 0.34 & 7.44 \\
& & 201 & 7.29 & 121.5 & 0.47 & 10.11 \\
& & 300 & 8.72 & 135.0 & 0.49 & 10.61 \\
& & 399 & 13.45 & 214.1 & 0.74 & 16.05 \\
& & 495 & 14.66 & 229.8 & 0.73 & 15.84 \\
& & 598 & 10.62 & 167.0 & 0.67 & 14.60 \\
\hline
\end{tabular}

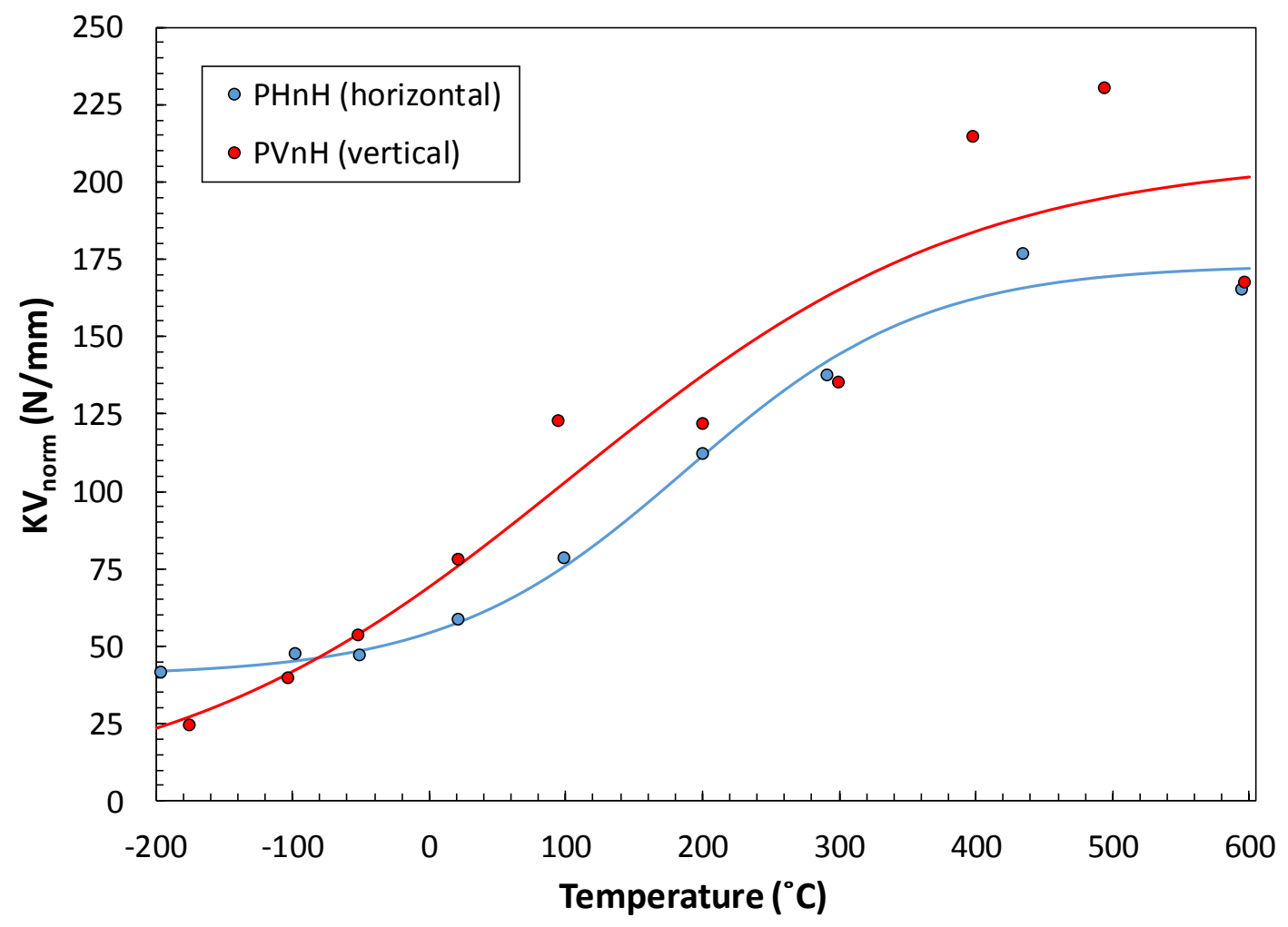

Figure 6 - Normalized absorbed energy for the non-HIPped specimens with printed notches. 


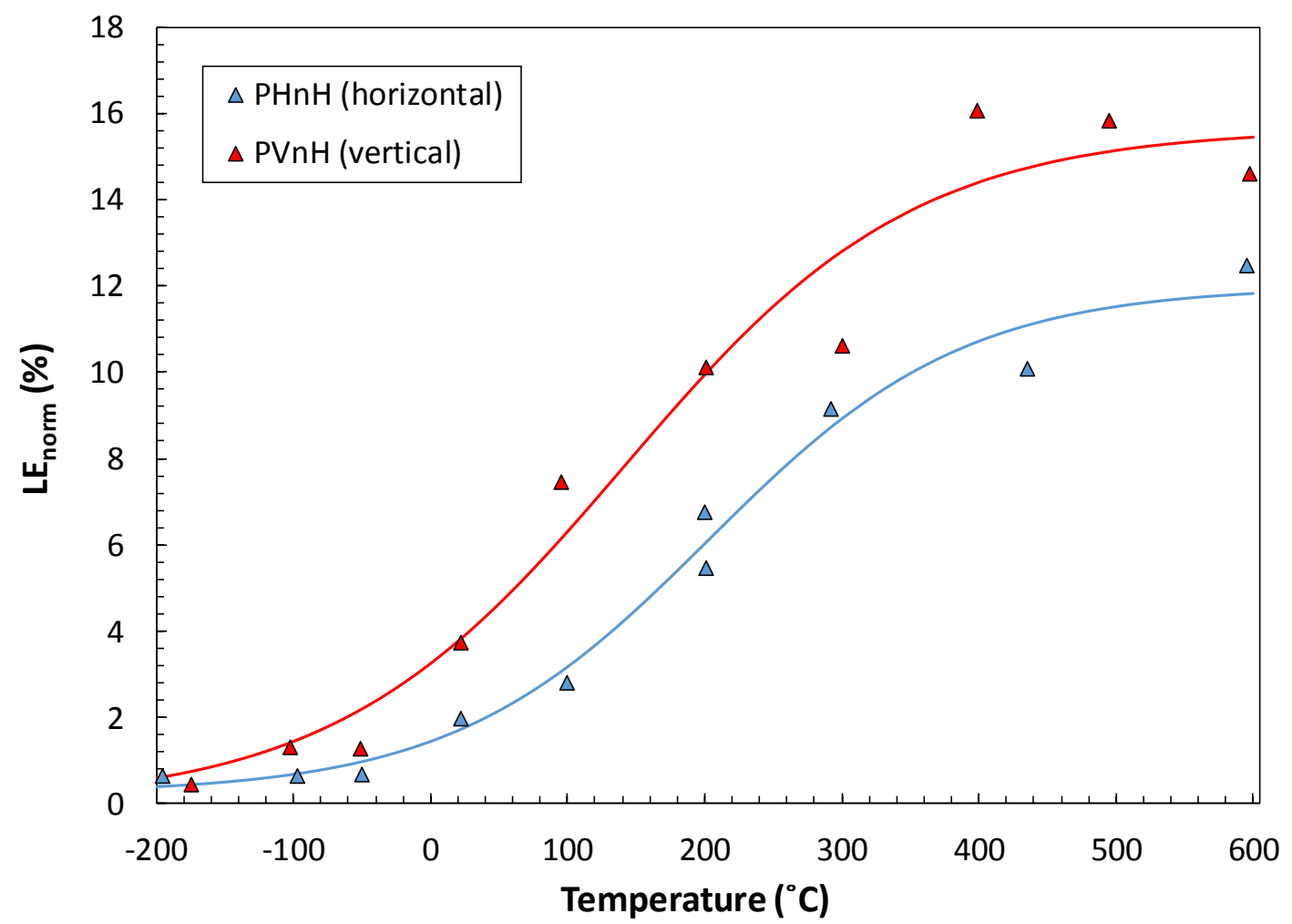

Figure 7 - Normalized lateral expansion for the non-HIPped specimens with printed notches.

Table 5 -Analysis results for the non-HIPped specimens with printed notches.

\begin{tabular}{|cccc|}
\hline Condition & Parameter & $\boldsymbol{K} \boldsymbol{V}_{\text {norm }}$ & $\boldsymbol{L E}_{\text {norm }}$ \\
\hline & $A$ & $106.8 \mathrm{~N} / \mathrm{mm}$ & $6.1 \%$ \\
& $B$ & $66.3 \mathrm{~N} / \mathrm{mm}$ & $5.9 \%$ \\
PHnH & $C$ & $175.3^{\circ} \mathrm{C}$ & $186.9^{\circ} \mathrm{C}$ \\
& $D B T T$ & $\mathbf{1 8 7 . 7}{ }^{\circ} \mathrm{C}$ & $\mathbf{2 0 2 . 8}{ }^{\circ} \mathrm{C}$ \\
& $\boldsymbol{U S E}$ & $\mathbf{1 7 3 . 1 \mathrm { N } / \mathrm { mm }}$ & - \\
& $R^{2}$ & 0.9272 & 0.9436 \\
\hline \multirow{4}{*}{ PVnH } & $A$ & $104.3 \mathrm{~N} / \mathrm{mm}$ & $7.8 \%$ \\
& $B$ & $104.3 \mathrm{~N} / \mathrm{mm}$ & $7.8 \%$ \\
& $C$ & $294.1^{\circ} \mathrm{C}$ & $211.1^{\circ} \mathrm{C}$ \\
& $D B T T$ & $\mathbf{1 0 2 . 6}{ }^{\circ} \mathbf{C}$ & $\mathbf{1 4 1 . 4}{ }^{\circ} \mathrm{C}$ \\
& $\boldsymbol{U S E}$ & $\mathbf{2 0 8 . 6 ~ N / m m}$ & - \\
& $R^{2}$ & 0.8489 & 0.9264 \\
\hline
\end{tabular}

\subsection{Printed notches, HIPped}

For the printed notch/HIPped condition, 20 specimens were tested between $-187{ }^{\circ} \mathrm{C}$ and $605^{\circ} \mathrm{C}, 10$ in horizontal direction $(\mathrm{PHH})$ and 10 in vertical direction (PVH). Test results are shown in Table 6, Figure 8 (normalized absorbed energy), and Figure 9 (normalized lateral expansion). 
Table 6 - Test results for the printed notch/HIPped specimens.

\begin{tabular}{|ccccccc|}
$\begin{array}{c}\text { Material } \\
\text { condition }\end{array}$ & Direction & $\begin{array}{c}\mathbf{T} \\
\left({ }^{\circ} \mathbf{C}\right)\end{array}$ & $\begin{array}{c}\boldsymbol{K} \boldsymbol{V} \\
(\mathbf{J})\end{array}$ & $\begin{array}{c}\boldsymbol{K} \boldsymbol{V}_{\text {norm }} \\
(\mathbf{N} / \mathbf{m m})\end{array}$ & $\begin{array}{c}\boldsymbol{L} \boldsymbol{E} \\
(\mathbf{m m})\end{array}$ & $\begin{array}{c}\boldsymbol{L} \boldsymbol{E}_{\text {norm }} \\
(\mathbf{\%})\end{array}$ \\
\hline & & -187 & 3.48 & 50.5 & 0.10 & 2.18 \\
& & -145 & 3.19 & 48.3 & 0.09 & 1.97 \\
& & -100 & 3.28 & 49.9 & 0.04 & 0.88 \\
$\mathbf{P H H}$ & Horizontal & -50 & 4.52 & 72.8 & 0.09 & 1.98 \\
& & 101 & 6.29 & 82.4 & 0.08 & 1.77 \\
& & 200 & 9.78 & 100.9 & 0.21 & 4.56 \\
& & 295 & 11.17 & 168.0 & 0.38 & 8.14 \\
& & 449 & 15.94 & 240.1 & 0.73 & 10.00 \\
& & 600 & 15.02 & 228.8 & 0.65 & 14.73 \\
& & -192 & 2.21 & 34.2 & 0.08 & 1.73 \\
& & -102 & 4.08 & 61.9 & 0.06 & 1.30 \\
PVH & & -51 & 4.35 & 65.8 & 0.12 & 2.61 \\
& & 22 & 6.02 & 97.4 & 0.20 & 4.41 \\
& & 103 & 10.45 & 151.1 & 0.37 & 7.94 \\
& & 196 & 11.93 & 185.6 & 0.55 & 11.93 \\
& & 314 & 15.38 & 244.0 & 0.82 & 17.67 \\
& & 398 & 16.45 & 239.1 & 0.68 & 14.47 \\
& & 500 & 16.96 & 263.6 & 0.85 & 18.48 \\
& & 605 & 15.53 & 237.1 & 0.72 & 15.65 \\
\hline
\end{tabular}

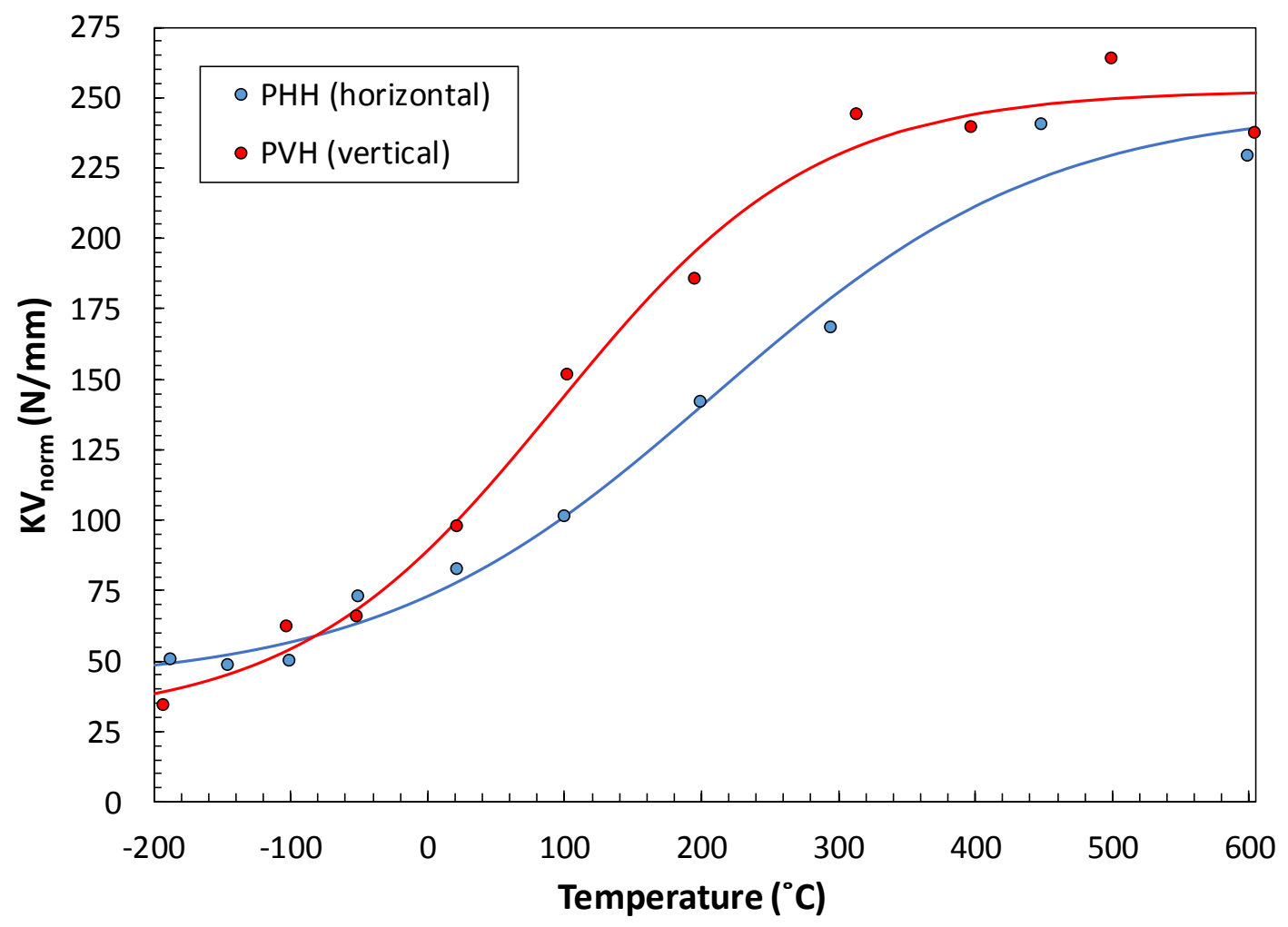

Figure 8 - Normalized absorbed energy for the HIPped specimens with printed notches. 


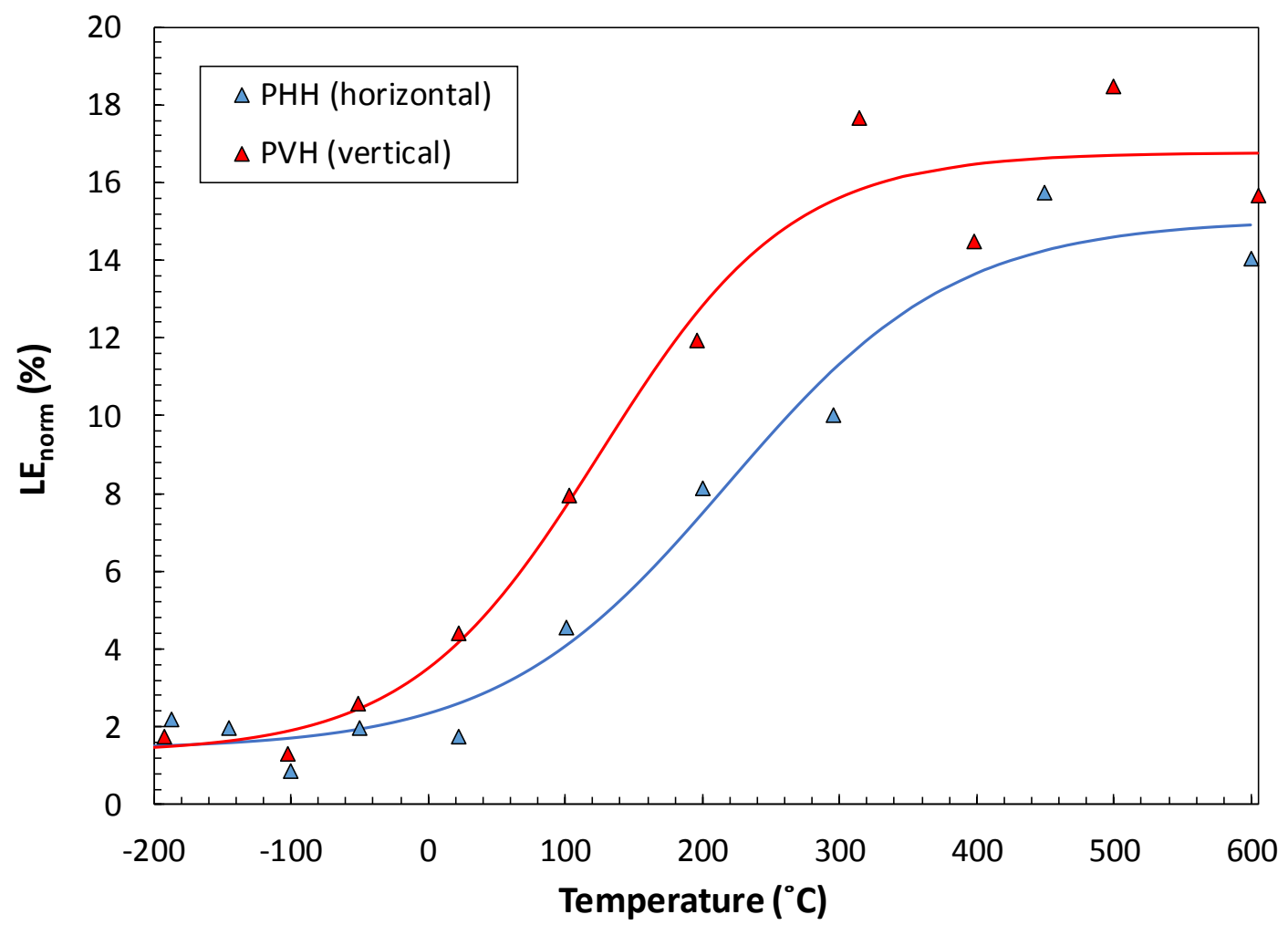

Figure 9 - Normalized lateral expansion for the HIPped specimens with printed notches.

The results obtained from the HIPped specimens confirm that the vertical direction possesses better impact toughness than the horizontal direction.

The analysis results for PHH and PVH are summarized in Table 7. The most significant results are highlighted in bold red.

Table 7 - Analysis results for the HIPped specimens with printed notches.

\begin{tabular}{|c|c|c|c|}
\hline Condition & Parameter & $K V_{\text {norm }}$ & $L E_{\text {norm }}$ \\
\hline \multirow{6}{*}{ PHH } & $A$ & $144.4 \mathrm{~N} / \mathrm{mm}$ & $8.2 \%$ \\
\hline & $B$ & $102.6 \mathrm{~N} / \mathrm{mm}$ & $6.8 \%$ \\
\hline & $C$ & $244.3^{\circ} \mathrm{C}$ & $166.6^{\circ} \mathrm{C}$ \\
\hline & $D B T T$ & $209.0^{\circ} \mathrm{C}$ & $218.4^{\circ} \mathrm{C}$ \\
\hline & USE & $247.0 \mathrm{~N} / \mathrm{mm}$ & - \\
\hline & $R^{2}$ & 0.9580 & 0.9016 \\
\hline \multirow{6}{*}{ PVH } & $\bar{A}$ & $140.6 \mathrm{~N} / \mathrm{mm}$ & $9.1 \%$ \\
\hline & $B$ & $112.0 \mathrm{~N} / \mathrm{mm}$ & $7.7 \%$ \\
\hline & $C$ & $189.2^{\circ} \mathrm{C}$ & $139.0^{\circ} \mathrm{C}$ \\
\hline & $D B T T$ & $94.1^{\circ} \mathrm{C}$ & $125.8^{\circ} \mathrm{C}$ \\
\hline & USE & $252.6 \mathrm{~N} / \mathrm{mm}$ & - \\
\hline & $R^{2}$ & 0.9060 & 0.8720 \\
\hline
\end{tabular}




\subsection{Machined notches, non-HIPped}

For the machined notch/non-HIPped condition, 20 specimens were tested between $-196{ }^{\circ} \mathrm{C}$ and $600{ }^{\circ} \mathrm{C}, 10$ in horizontal direction $(\mathrm{MHnH})$ and 10 in vertical direction $(\mathrm{MVnH})$. Test results are shown in Table 8, Figure 10 (normalized absorbed energy) and Figure 11 (normalized lateral expansion).

Table 8 - Test results for the machined notch/non-HIPped specimens.

\begin{tabular}{|c|c|c|c|c|c|c|}
\hline $\begin{array}{l}\text { Material } \\
\text { condition }\end{array}$ & Direction & $\begin{array}{c}\mathbf{T} \\
\left({ }^{\circ} \mathbf{C}\right)\end{array}$ & $\begin{array}{l}K V \\
(\mathbf{J})\end{array}$ & $\begin{array}{l}K V_{\text {norm }} \\
(\mathrm{N} / \mathbf{m m})\end{array}$ & $\begin{array}{c}L E \\
(\mathbf{m m})\end{array}$ & $\begin{array}{c}L E_{\text {norm }} \\
(\%)\end{array}$ \\
\hline \multirow{10}{*}{ MHnH } & \multirow{10}{*}{ Horizontal } & -196 & 2.39 & 29.9 & 0.04 & 0.80 \\
\hline & & -99 & 2.63 & 32.9 & 0.12 & 2.40 \\
\hline & & -50 & 3.60 & 45.0 & 0.08 & 1.60 \\
\hline & & 22 & 4.48 & 56.0 & 0.08 & 1.60 \\
\hline & & 101 & 5.74 & 71.8 & 0.17 & 3.40 \\
\hline & & 200 & 9.03 & 112.9 & 0.24 & 4.80 \\
\hline & & 300 & 11.52 & 144.0 & 0.49 & 9.80 \\
\hline & & 400 & 11.62 & 145.3 & 0.45 & 9.00 \\
\hline & & 500 & 15.28 & 191.0 & 0.70 & 14.00 \\
\hline & & 598 & 14.61 & 182.6 & 0.72 & 14.40 \\
\hline \multirow{10}{*}{ MVnH } & \multirow{10}{*}{ Vertical } & -158 & 2.64 & 33.0 & 0.00 & 0.00 \\
\hline & & -100 & 3.51 & 43.9 & 0.08 & 1.60 \\
\hline & & -51 & 3.73 & 46.6 & 0.10 & 2.00 \\
\hline & & 22 & 5.33 & 66.6 & 0.14 & 2.80 \\
\hline & & 102 & 7.46 & 93.3 & 0.25 & 5.00 \\
\hline & & 195 & 8.05 & 100.6 & 0.30 & 6.00 \\
\hline & & 280 & 11.52 & 144.0 & 0.50 & 10.00 \\
\hline & & 400 & 11.93 & 149.1 & 0.47 & 9.40 \\
\hline & & 500 & 12.70 & 158.8 & 0.60 & 12.00 \\
\hline & & 600 & 14.22 & 177.8 & 0.55 & 11.00 \\
\hline
\end{tabular}

Based on the results obtained, the difference between the two orientations is less significant than for the printed notches in the non-HIPped condition. In this case, the horizontal direction shows better upper shelf impact toughness than the vertical direction.

The analysis results for $\mathrm{MHnH}$ and $\mathrm{MVnH}$ are summarized in Table 9. The most significant results are highlighted in bold red. 


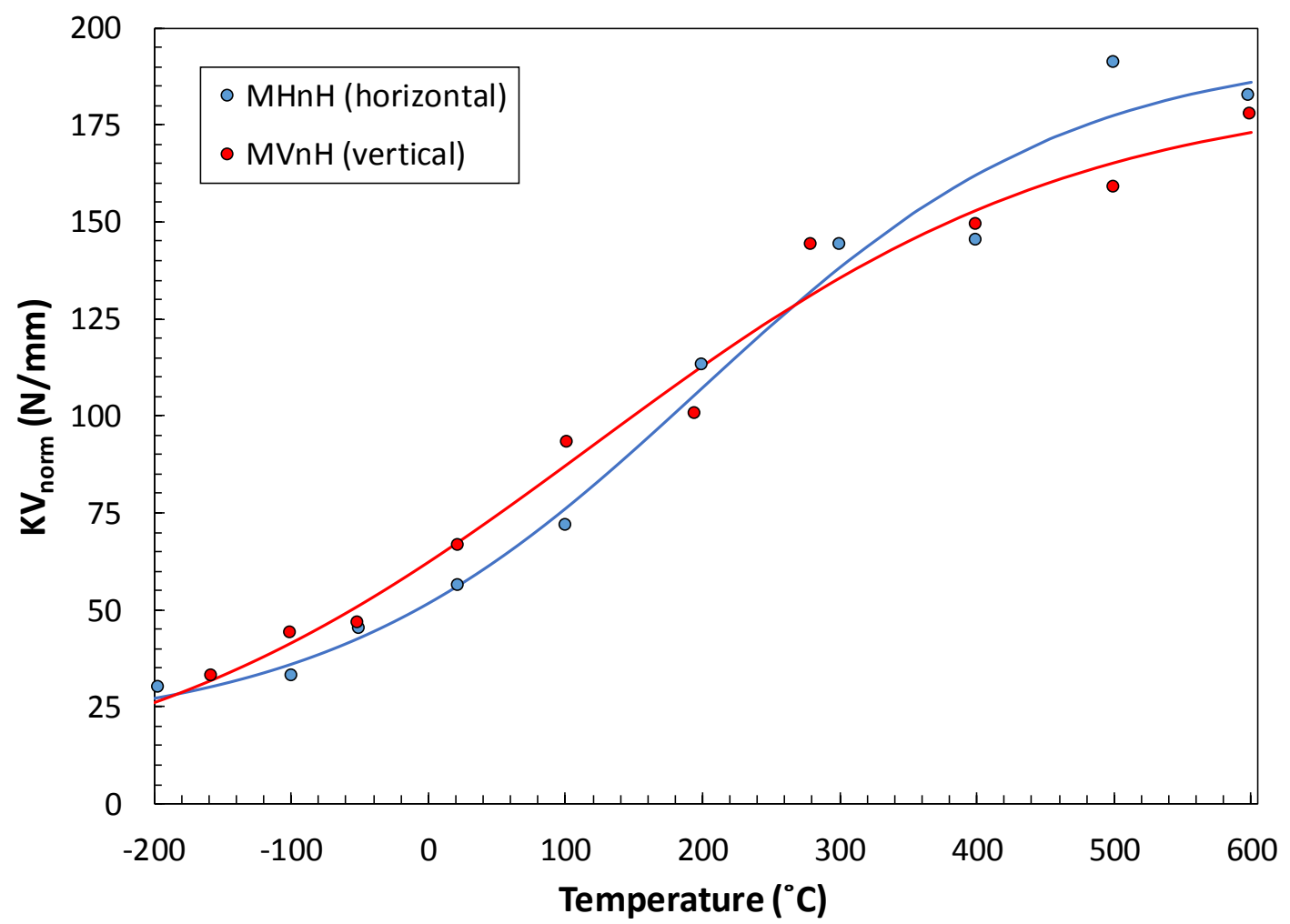

Figure 10 - Normalized absorbed energy for the non-HIPped specimens with machined notches.

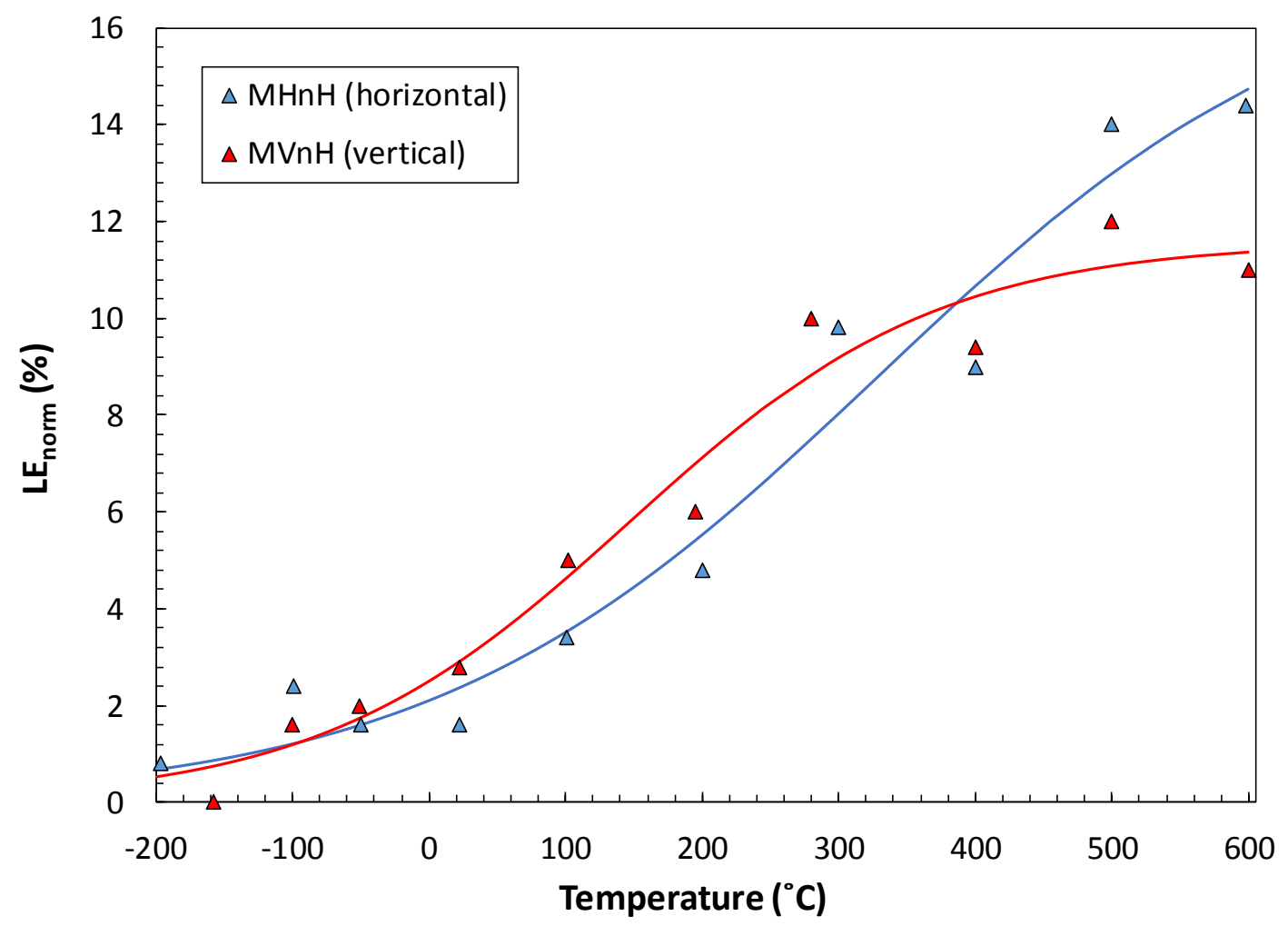

Figure 11 - Normalized lateral expansion for the non-HIPped specimens with machined notches. 
Table 9 - Analysis results for the non-HIPped specimens with machined notches.

\begin{tabular}{|cccc|}
\hline Condition & Parameter & $\boldsymbol{K} \boldsymbol{V}_{\text {norm }}$ & $\boldsymbol{L E}_{\text {norm }}$ \\
\hline & $A$ & $106.6 \mathrm{~N} / \mathrm{mm}$ & $8.8 \%$ \\
& $B$ & $88.3 \mathrm{~N} / \mathrm{mm}$ & $8.8 \%$ \\
PHH & $C$ & $271.9^{\circ} \mathrm{C}$ & $330.2^{\circ} \mathrm{C}$ \\
& $D B T T$ & $\mathbf{1 9 7 . 4}{ }^{\circ} \mathrm{C}$ & $\mathbf{3 2 8 . 6}{ }^{\circ} \mathrm{C}$ \\
& $\boldsymbol{U S E}$ & $\mathbf{1 9 4 . 8 \mathrm { N } / \mathrm { mm }}$ & - \\
& $R^{2}$ & 0.9634 & 0.9208 \\
\hline \multirow{6}{*}{ PVH } & $A$ & $92.2 \mathrm{~N} / \mathrm{mm}$ & $5.8 \%$ \\
& $B$ & $92.2 \mathrm{~N} / \mathrm{mm}$ & $5.8 \%$ \\
& $C$ & $355.3^{\circ} \mathrm{C}$ & $228.0{ }^{\circ} \mathrm{C}$ \\
& $D B T T$ & $\mathbf{1 1 9 . 5}{ }^{\circ} \mathrm{C}$ & $\mathbf{1 4 7 . 0}{ }^{\circ} \mathrm{C}$ \\
& $\boldsymbol{U S E}$ & $\mathbf{1 8 4 . 5} \mathrm{N} / \mathrm{mm}$ & - \\
& $R^{2}$ & 0.9693 & 0.9386 \\
\hline
\end{tabular}

\subsection{Machined notches, HIPped}

For the machined notch/HIPped condition, 20 specimens were tested between $-168{ }^{\circ} \mathrm{C}$ and $600{ }^{\circ} \mathrm{C}, 10$ in horizontal direction $(\mathrm{MHH})$ and 10 in vertical direction (MVH). Test results are shown in Table 10, Figure 12 (normalized absorbed energy) and Figure 13 (normalized lateral expansion).

Table 10 - Test results for the machined notch/HIPped specimens.

\begin{tabular}{|ccccccc|}
$\begin{array}{c}\text { Material } \\
\text { condition }\end{array}$ & Direction & $\begin{array}{c}\mathbf{T} \\
\left({ }^{\circ} \mathbf{C}\right)\end{array}$ & $\begin{array}{c}\boldsymbol{K} \boldsymbol{V} \\
(\mathbf{J})\end{array}$ & $\begin{array}{c}\boldsymbol{K} \boldsymbol{V}_{\text {norm }} \\
(\mathbf{N} / \mathbf{m m})\end{array}$ & $\begin{array}{c}\boldsymbol{L} \boldsymbol{E} \\
(\mathbf{m m})\end{array}$ & $\begin{array}{c}\boldsymbol{L} \boldsymbol{E}_{\text {norm }} \\
(\boldsymbol{\%})\end{array}$ \\
\hline \multirow{6}{*}{ MHH } & & -168 & 3.55 & 44.4 & 0.05 & 1.0 \\
& & -100 & 4.28 & 53.5 & 0.10 & 2.0 \\
& & -49 & 4.73 & 59.1 & 0.15 & 3.0 \\
& & 22 & 6.00 & 75.0 & 0.17 & 3.4 \\
& & 100 & 8.52 & 106.5 & 0.36 & 7.2 \\
& & 201 & 13.04 & 163.0 & 0.46 & 9.2 \\
& & 293 & 16.15 & 201.9 & 0.60 & 12.0 \\
MVH & & 590 & 16.01 & 200.1 & 0.58 & 11.6 \\
& & 600 & 11.65 & 214.0 & 0.59 & 11.8 \\
& & 23.17 & 289.6 & 0.57 & 11.4 \\
\hline & & -168 & 3.16 & 39.5 & 0.07 & 1.4 \\
& & -100 & 5.41 & 67.6 & 0.17 & 3.4 \\
& & -50 & 6.34 & 79.3 & 0.17 & 3.4 \\
& & 22 & 8.77 & 109.6 & 0.25 & 5.0 \\
& & 100 & 13.02 & 162.8 & 0.46 & 9.2 \\
& 197 & 17.79 & 222.4 & 0.63 & 12.6 \\
& & 303 & 17.98 & 224.8 & 0.78 & 15.6 \\
& & 490 & 19.35 & 241.9 & 0.78 & 15.6 \\
& & 498 & 18.37 & 229.6 & 0.78 & 15.6 \\
& & 595 & 23.45 & 293.1 & 0.65 & 13.0 \\
\hline
\end{tabular}




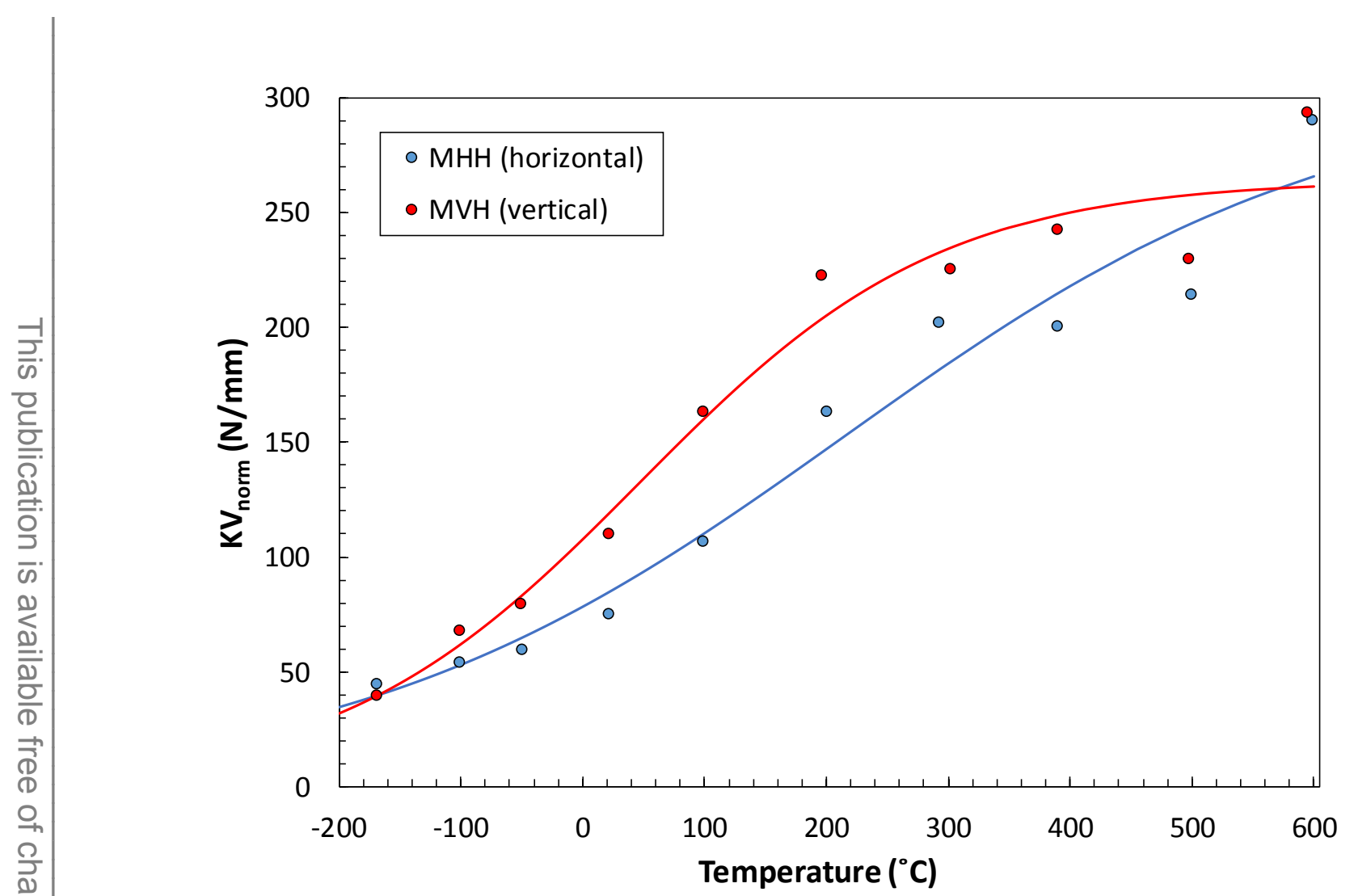

Figure 12 - Normalized absorbed energy for the HIPped specimens with machined notches.

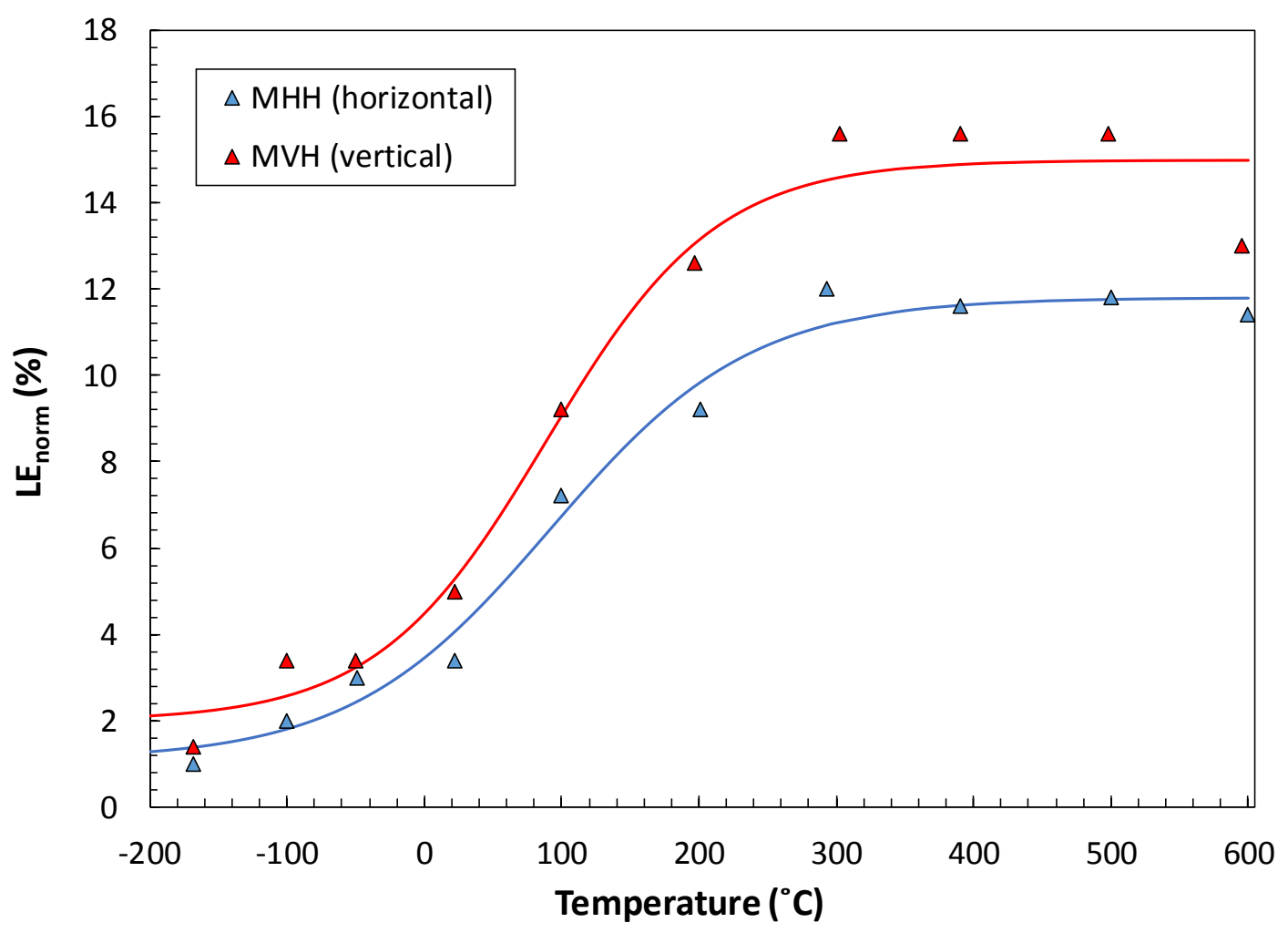

Figure 13 - Normalized lateral expansion for the HIPped specimens with machined notches. 
The vertical direction appears to have better impact toughness than the horizontal direction, based on the results obtained in the transition region. In upper shelf, however, the horizontal specimens exhibit an increasing trend for absorbed energy even at $600{ }^{\circ} \mathrm{C}$, whereas the vertical specimens seem to have reached a plateau. This complicates the comparison between orientations in terms of upper shelf impact toughness. Note that, based on normalized lateral expansion (Figure 13), both directions seem to have reached their upper shelf plateau at $300{ }^{\circ} \mathrm{C}$.

The analysis results for $\mathrm{MHH}$ and $\mathrm{MVH}$ are summarized in Table 11. The most significant results are highlighted in bold red.

\section{Table 11 - Analysis results for the HIPped specimens with machined notches.}

\begin{tabular}{|c|c|c|c|}
\hline Condition & Parameter & $K V_{\text {norm }}$ & $L E_{\text {norm }}$ \\
\hline \multirow{6}{*}{ МНH } & $A$ & $152.7 \mathrm{~N} / \mathrm{mm}$ & $8.8 \%$ \\
\hline & $B$ & $152.7 \mathrm{~N} / \mathrm{mm}$ & $8.8 \%$ \\
\hline & C & $405.4^{\circ} \mathrm{C}$ & $330.2^{\circ} \mathrm{C}$ \\
\hline & DBTT & $215.0^{\circ} \mathrm{C}$ & $328.6^{\circ} \mathrm{C}$ \\
\hline & USE & $305.4 \mathrm{~N} / \mathrm{mm}$ & - \\
\hline & $R^{2}$ & 0.9599 & 0.8696 \\
\hline \multirow{6}{*}{ MVH } & $A$ & $132.2 \mathrm{~N} / \mathrm{mm}$ & $8.5 \%$ \\
\hline & $B$ & $132.2 \mathrm{~N} / \mathrm{mm}$ & $6.5 \%$ \\
\hline & C & $247.0^{\circ} \mathrm{C}$ & $123.7^{\circ} \mathrm{C}$ \\
\hline & DBTT & $46.6^{\circ} \mathrm{C}$ & $89.1^{\circ} \mathrm{C}$ \\
\hline & USE & $264.4 \mathrm{~N} / \mathrm{mm}$ & - \\
\hline & $R^{2}$ & 0.9199 & 0.8135 \\
\hline
\end{tabular}

\subsection{Summary of results obtained}

We have summarized in Table 12 the values of $D B T T_{K V}$ (ductile-to-brittle transition temperature based on normalized absorbed energy), $D B T T_{L E}$ (ductile-to-brittle transition temperature based on normalized lateral expansion), and $U S E_{\text {norm }}$ (normalized upper shelf energy) obtained from the different conditions.

For several of the investigated conditions, the transition curves obtained did not show a clear plateau of normalized absorbed energy and/or normalized lateral expansion. Therefore, the corresponding values of $D B T T$ or $U S E_{n o r m}$ are associated to significant uncertainty and do not allow a reliable comparison between the different conditions.

Hence, for comparison purposes we decided to use primarily the values of normalized absorbed energy calculated from the transition curves at room temperature $\left(K V_{n o r m, 21^{\circ}}\right)$ and 350 ${ }^{\circ} \mathrm{C}^{8}\left(K V_{n o r m}, 350^{\circ} \mathrm{C}\right)$. These values are included in Table 12 and illustrated in Figure $12\left(21{ }^{\circ} \mathrm{C}\right)$ and Figure $13\left(350^{\circ} \mathrm{C}\right)$. To facilitate the examination of Figure 12 and Figure 13, bars for horizontal

\footnotetext{
${ }^{8} 350{ }^{\circ} \mathrm{C}$ is generally considered the highest service temperature for Ti-6Al-4V, see page 1 .
} 
specimens are red and bars for vertical specimens are green. Different patterns are used for non-HIPped and HIPped specimens, and for printed and machined notches.

Table 12 - Summary of the results obtained from instrumented Charpy tests.

\begin{tabular}{|c|c|c|c|c|c|c|c|}
\hline Condition & Orientation & HIPped? & $\begin{array}{c}D^{D B T T_{K V}} \\
\left({ }^{\circ} \mathrm{C}\right)\end{array}$ & $\begin{array}{c}D_{B C T} T_{L E} \\
\left({ }^{\circ} \mathbf{C}\right)\end{array}$ & $\begin{array}{l}\boldsymbol{U} \boldsymbol{U S E _ { \text { norm } }} \\
(\mathbf{N} / \mathbf{m m})\end{array}$ & $\begin{array}{c}K V_{\text {norm }, 21^{\circ} \mathrm{C}} \\
(\mathrm{N} / \mathrm{mm})\end{array}$ & $\begin{array}{c}K V_{\text {norm }, 350^{\circ} \mathrm{C}}(\mathrm{N} / \mathrm{mm})\end{array}$ \\
\hline Baseline [B1-B2] & - & NO & 220.7 & 200.8 & 288.9 & 57.6 & 245.4 \\
\hline PHnH & horizontal & \multirow{2}{*}{ NO } & 187.7 & 202.8 & 173.1 & 57.7 & 155.1 \\
\hline PVnH & vertical & & 102.6 & 141.4 & 208.6 & 76.1 & 175.9 \\
\hline PHH & horizontal & \multirow{2}{*}{ YES } & 209.0 & 218.4 & 247.0 & 78.1 & 197.8 \\
\hline PVH & vertical & & 189.2 & 139.0 & 252.6 & 99.3 & 238.5 \\
\hline MHnH & horizontal & \multirow{2}{*}{ NO } & 197.4 & 328.6 & 194.8 & 56.2 & 151.4 \\
\hline MVnH & vertical & & 119.5 & 147.0 & 184.5 & 67.3 & 144.9 \\
\hline MHH & horizontal & \multirow{2}{*}{ YES } & 215.0 & 92.0 & 305.4 & 84.7 & 201.7 \\
\hline MVH & vertical & & 46.6 & 89.1 & 264.4 & 118.5 & 243.5 \\
\hline
\end{tabular}

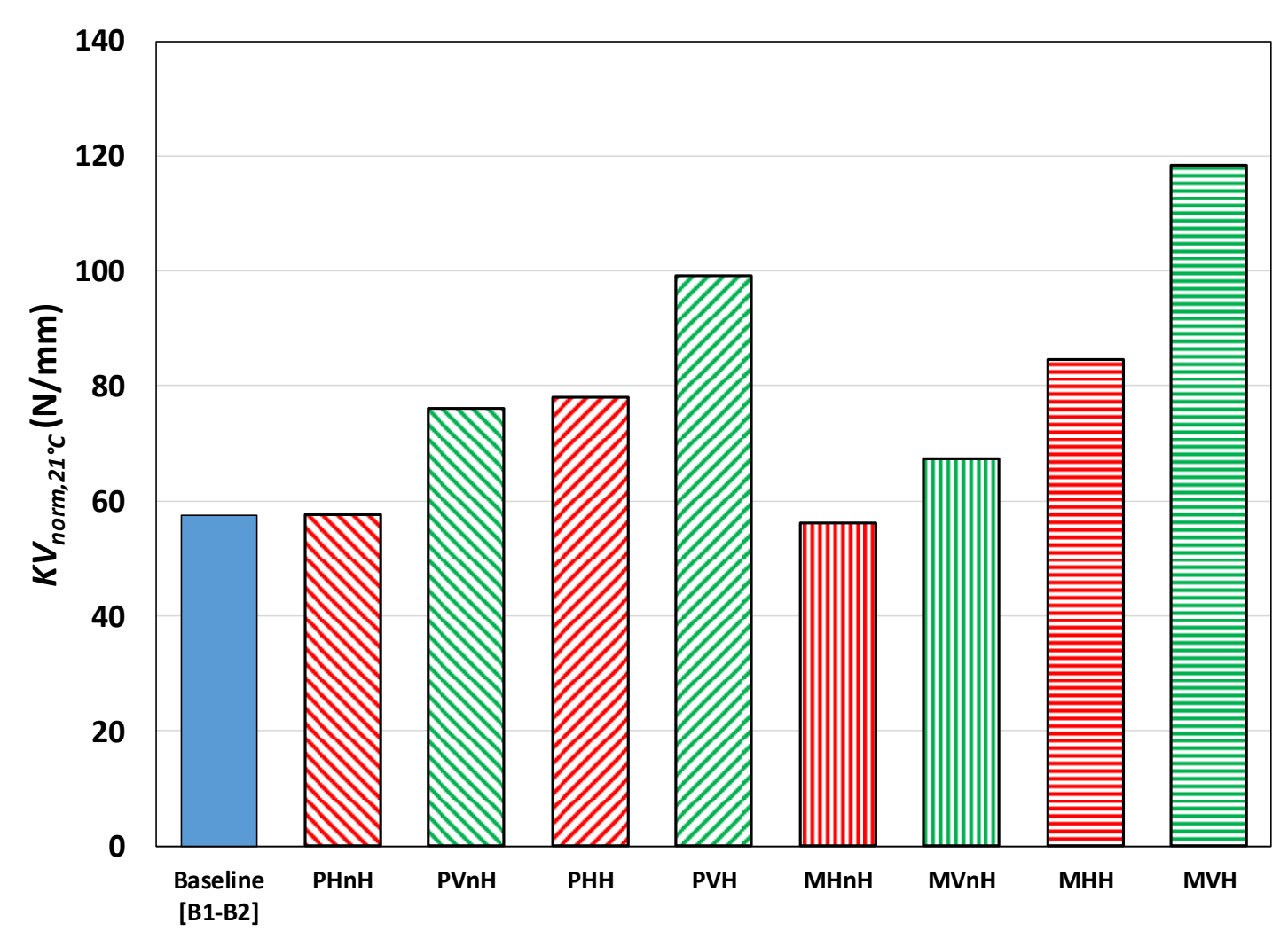

Figure 14 - Normalized absorbed energies at $21{ }^{\circ} \mathrm{C}$ for the investigated conditions.

LEGEND - PH $=$ printed notch, horizontal direction

$\mathrm{PV}=$ printed notch, vertical direction

$\mathrm{MH}=$ machined notch, horizontal direction

$\mathrm{MV}=$ machined notch, vertical direction

$(X X) \mathrm{nH}=$ non-HIPped 


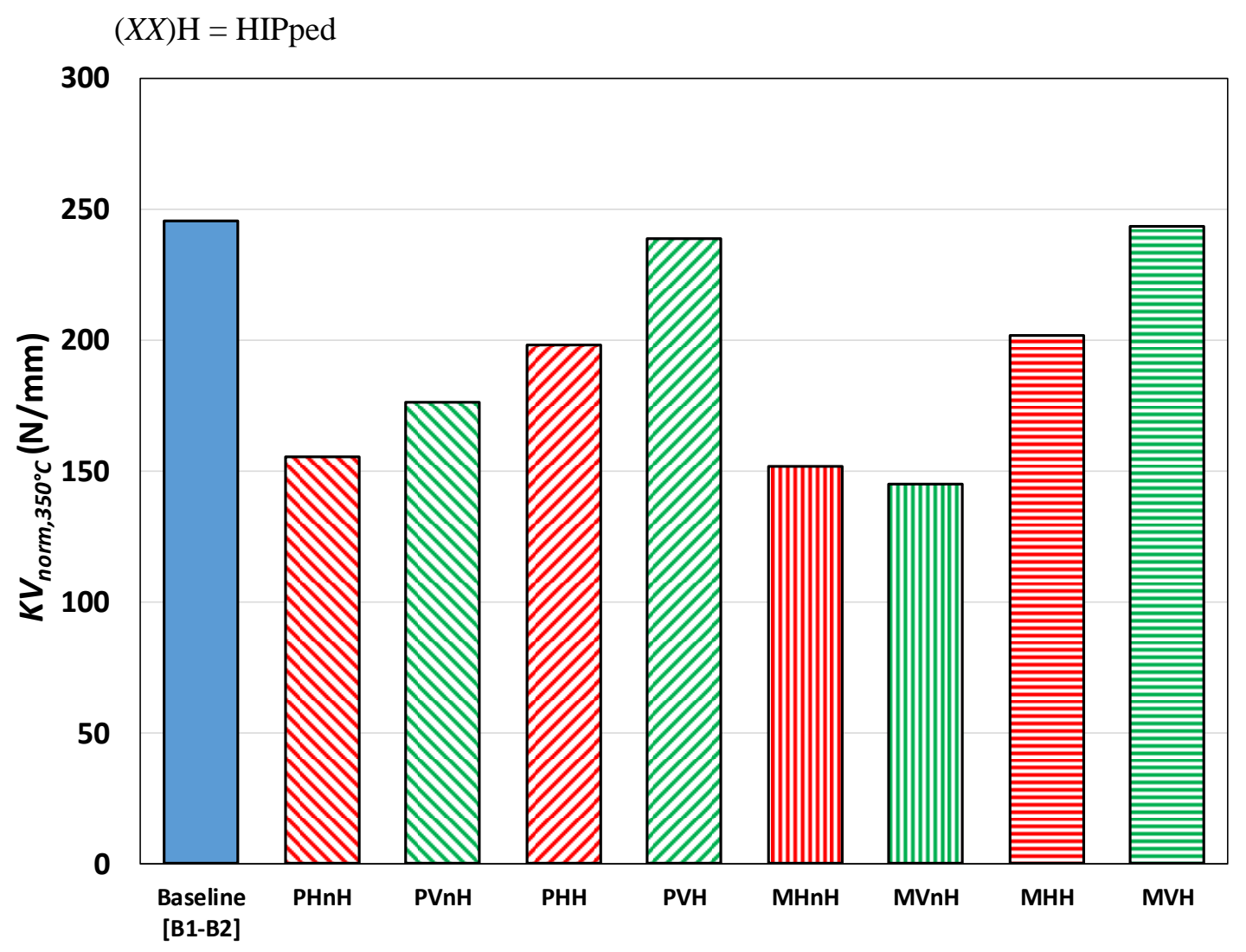

Figure 15 - Normalized absorbed energies at $350{ }^{\circ} \mathrm{C}$ for the investigated conditions.

The results presented in Table 12, Figure 14, and Figure 15 will be discussed in detail in the following section.

$$
\begin{aligned}
\text { LEGEND }- & \mathrm{PH}=\text { printed notch, horizontal direction } \\
& \mathrm{PV}=\text { printed notch, vertical direction } \\
& \mathrm{MH}=\text { machined notch, horizontal direction } \\
& \mathrm{MV}=\text { machined notch, vertical direction } \\
& (X X) \mathrm{nH}=\text { non-HIPped } \\
& (X X) \mathrm{H}=\text { HIPped }
\end{aligned}
$$




\section{Discussion}

\subsection{Effect of specimen orientation}

Specimens in the vertical orientation exhibited better impact toughness than those in the horizontal orientation. This effect appears clear for all conditions examined, except for the HIPped specimens with machined notches (Figure 10), where the difference appears small. However, additional data in both the lower and upper shelf regions might bring these latter data sets in better agreement with the other conditions.

The effect of orientation on the Charpy transition curves for normalized absorbed energy and lateral expansion is also illustrated by the comparison of experimental data and transition curves for printed notches (Figure 16 and Figure 17) and machined notches (Figure 18 and Figure 19).

With reference to the data reported in Table 12 , at room temperature $\left(21^{\circ} \mathrm{C}\right)$ the increase in normalized absorbed energy from horizontal to vertical specimens ranges from $20 \%$ to $40 \%$, while the variation at $350{ }^{\circ} \mathrm{C}$ is between $-4 \%$ (slight decrease for non-HIPped specimens with machined notches) and $21 \%$. The effect of specimen orientation appears less pronounced as test temperature increases.

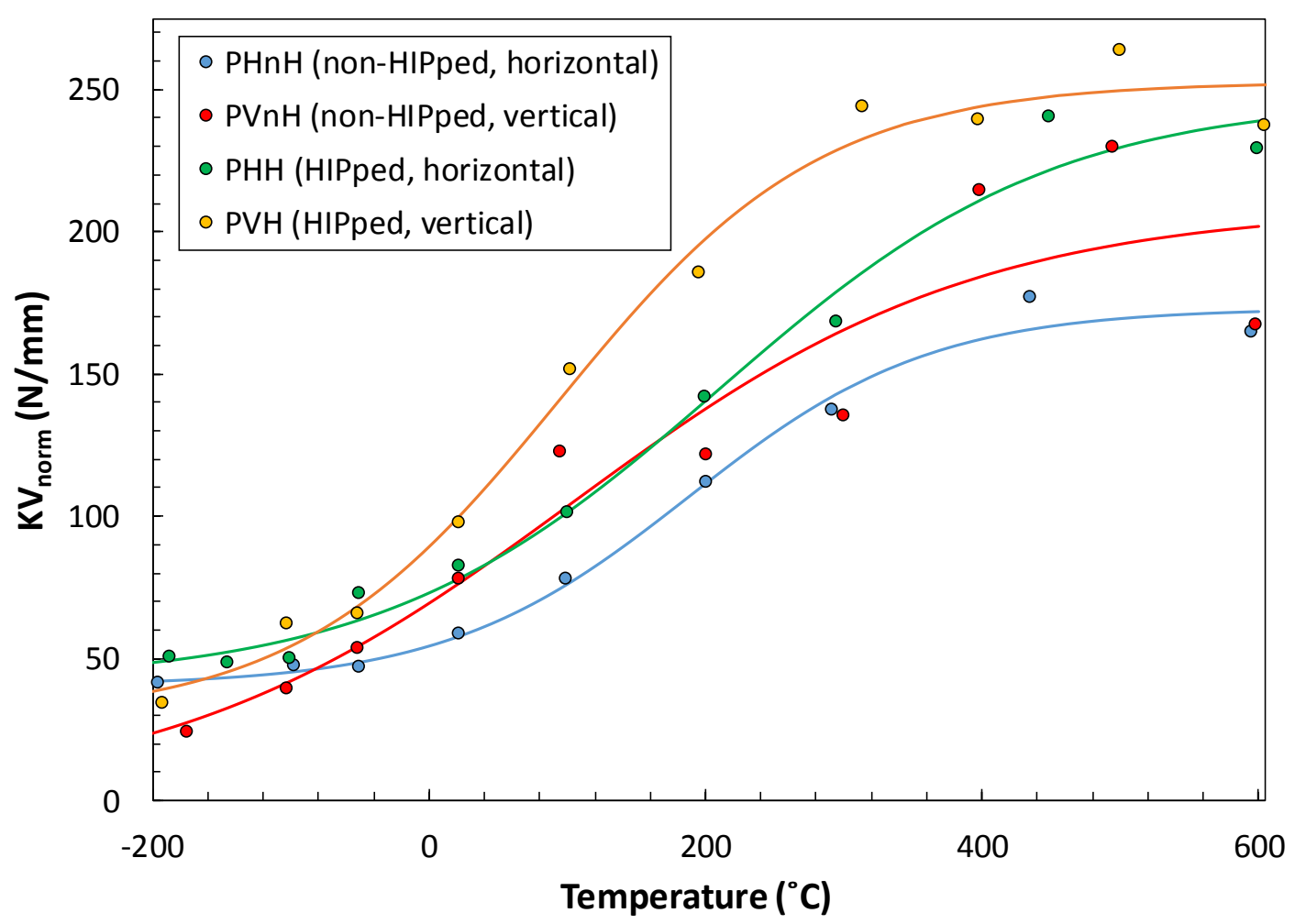

Figure 16 - Normalized absorbed energy data and transition curves for specimens with printed notches. 


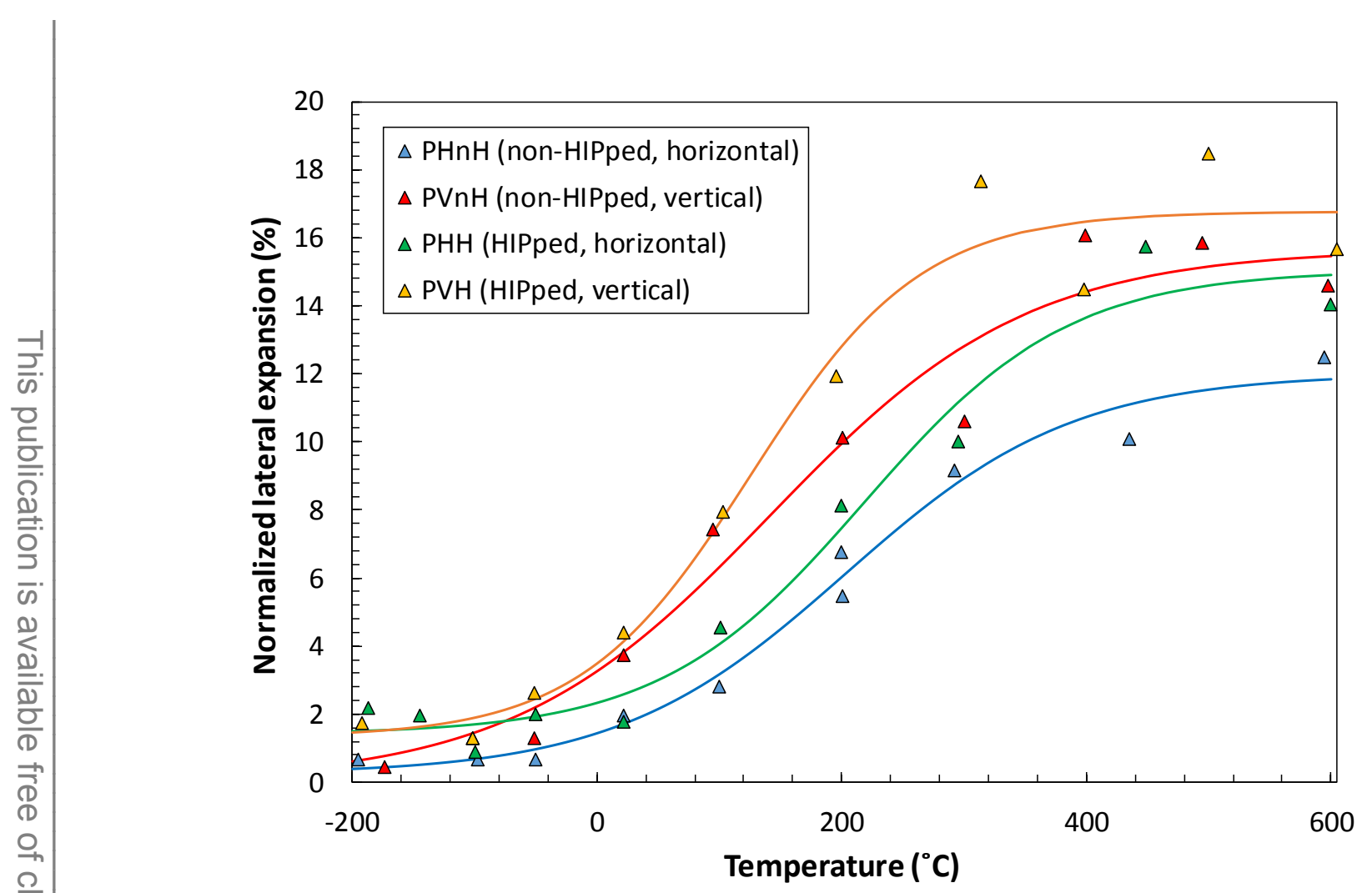

Figure 17 - Normalized lateral expansion data and transition curves for specimens with printed notches.

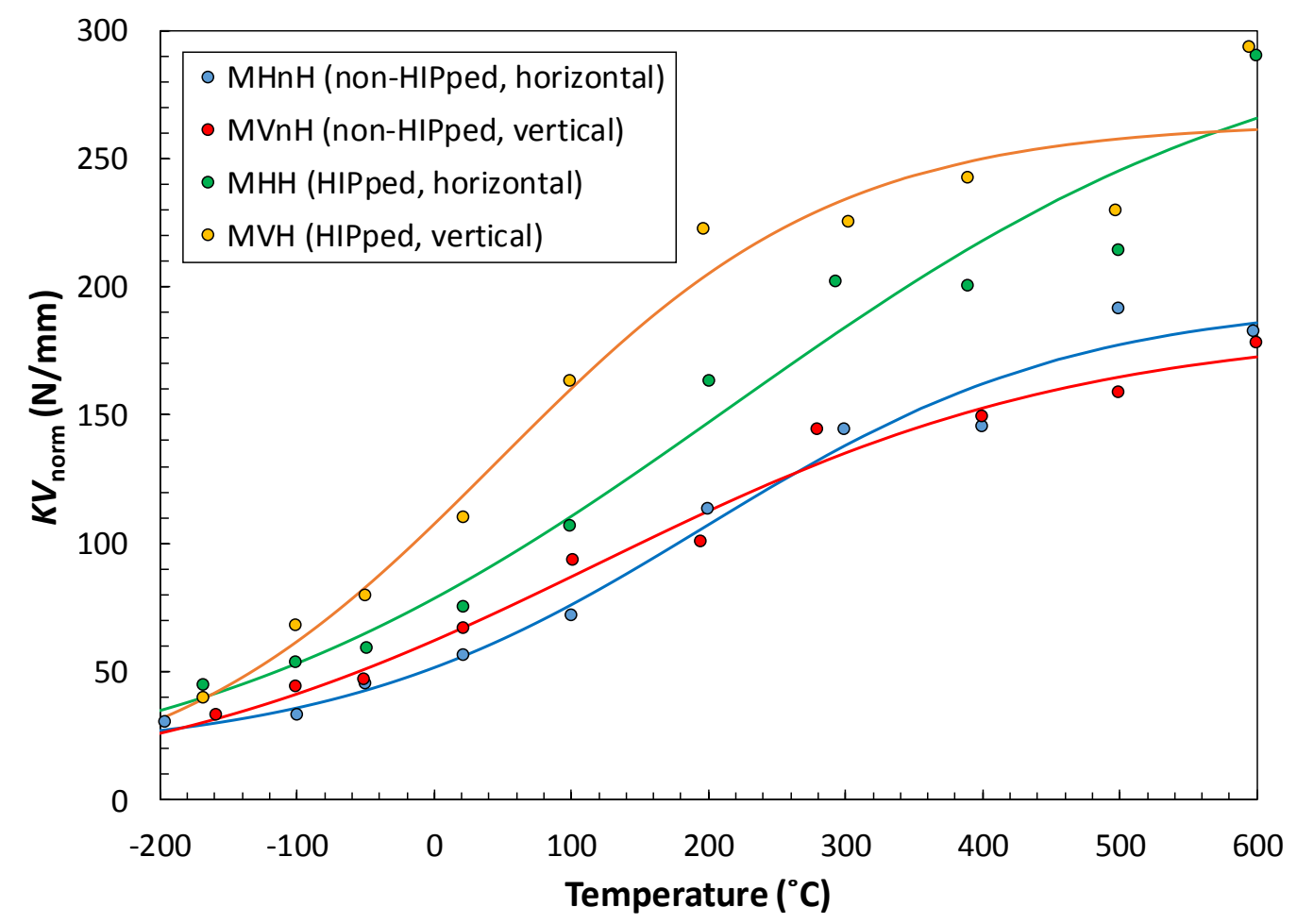

Figure 18 - Normalized absorbed energy data and transition curves for specimens with machined notches. 


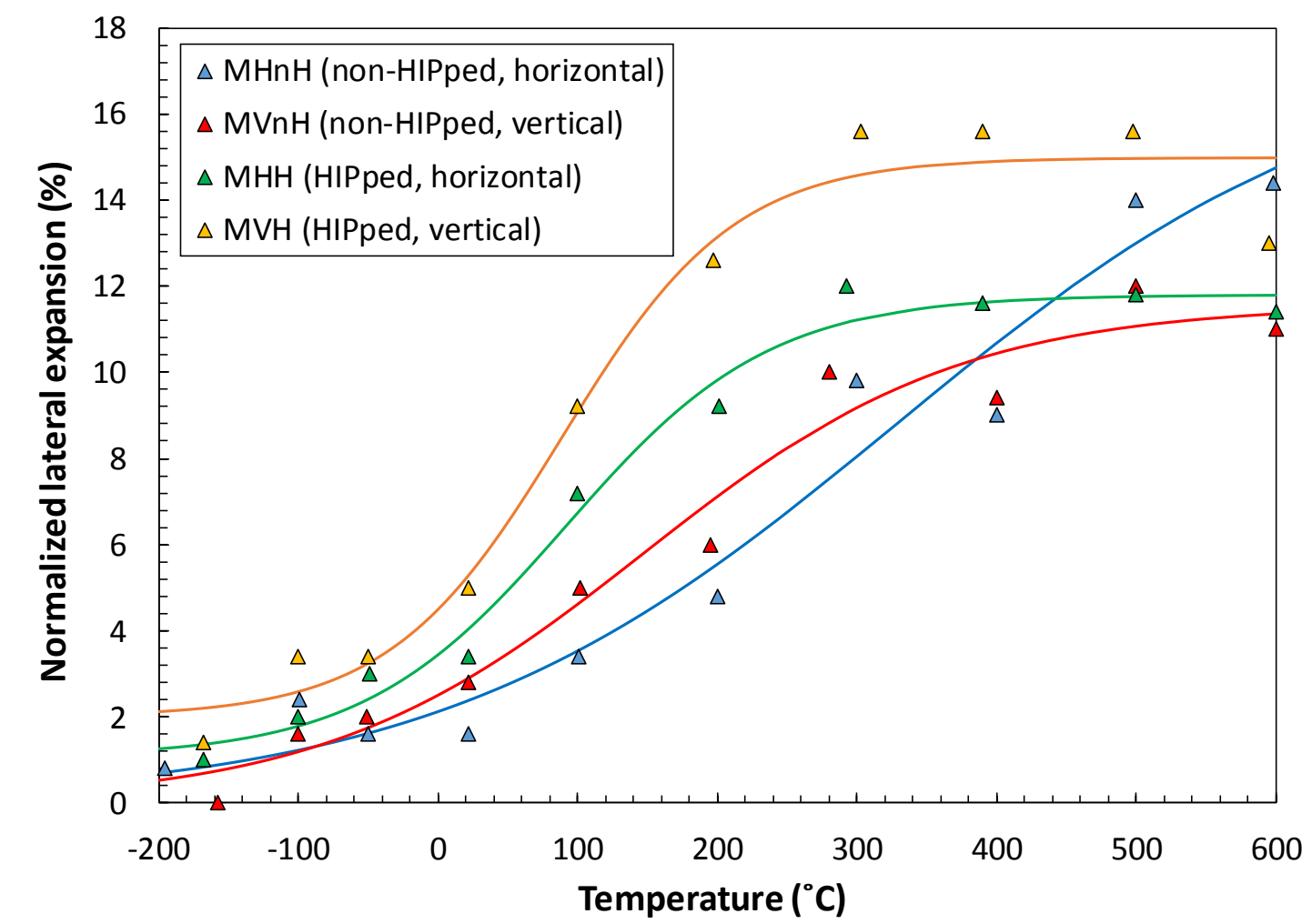

Figure 19 - Normalized lateral expansion data and transition curves for specimens with machined notches.

\subsection{Non-HIPped vs. HIPped}

Hot Isostatic Pressing (HIPping) tends to improve a material's mechanical properties by reducing its porosity and increasing its density [8]. For a material which is manufactured by additive manufacturing and is therefore expected to exhibit significant porosity, HIPping should bring significant improvements in fracture toughness.

The improvement in impact toughness is clearly visible from the results we obtained, as illustrated in terms of normalized absorbed energy for vertically-manufactured specimens in Figure 20 (printed notches) and Figure 21 (machined notches).

In terms of normalized absorbed energy, HIPping induced an increase of impact toughness between $30 \%$ and $76 \%$ at room temperature, and between $28 \%$ and $68 \%$ at $350{ }^{\circ} \mathrm{C}$. 


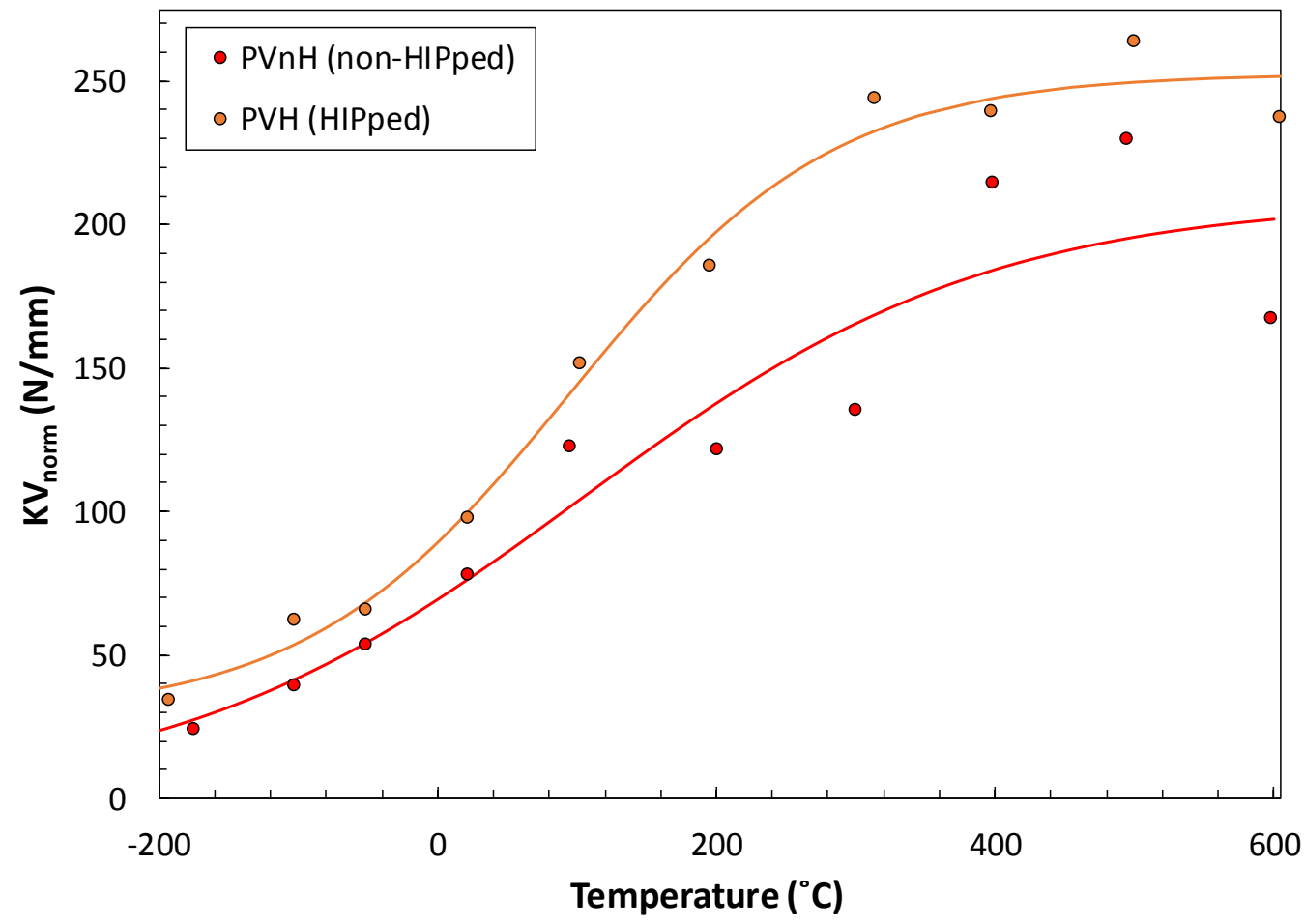

Figure 20 - Comparison between non-HIPped and HIPped specimens (printed notches, vertical direction).

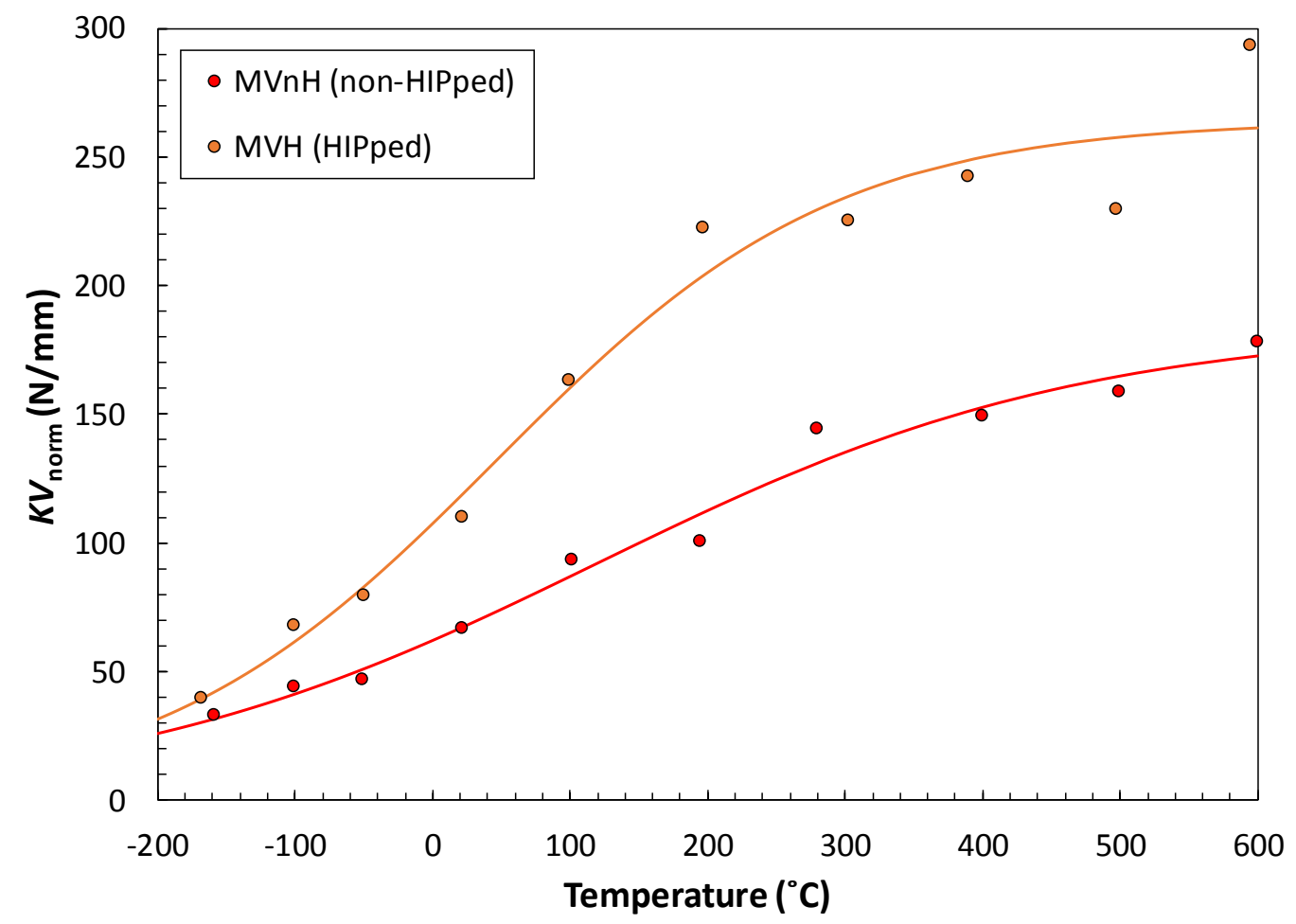

Figure 21 - Comparison between non-HIPped and HIPped specimens (machined notches, vertical direction). 


\subsection{Printed vs. machined notches}

The comparisons between printed and machined notches for the two orientations (horizontal and vertical) and the non-HIPped and HIPped conditions are provided in Figure 22 to Figure 25 (normalized absorbed energy) and Figure 26 to Figure 29 (normalized lateral expansion).

Although the asperities of the printed notches were expected to provide additional crack initiation sites and therefore induce lower impact toughness, particularly in the lower shelf and lower transition region, our results do not confirm these expectations. Transition curves obtained for printed and machined notches indicate substantially equivalent fracture behavior. This is confirmed by the comparison of normalized absorbed energy values in Table 12.

Nevertheless, we observe that, at both $21{ }^{\circ} \mathrm{C}$ (Figure 14) and $350{ }^{\circ} \mathrm{C}$ (Figure 15), normalized absorbed energy for printed notches is higher than machined notches for all non-HIPped conditions and lower for all HIPped conditions. However, in the absence of standard deviations for test results obtained at a single temperature, it is not possible to comment on the statistical significance of such differences.

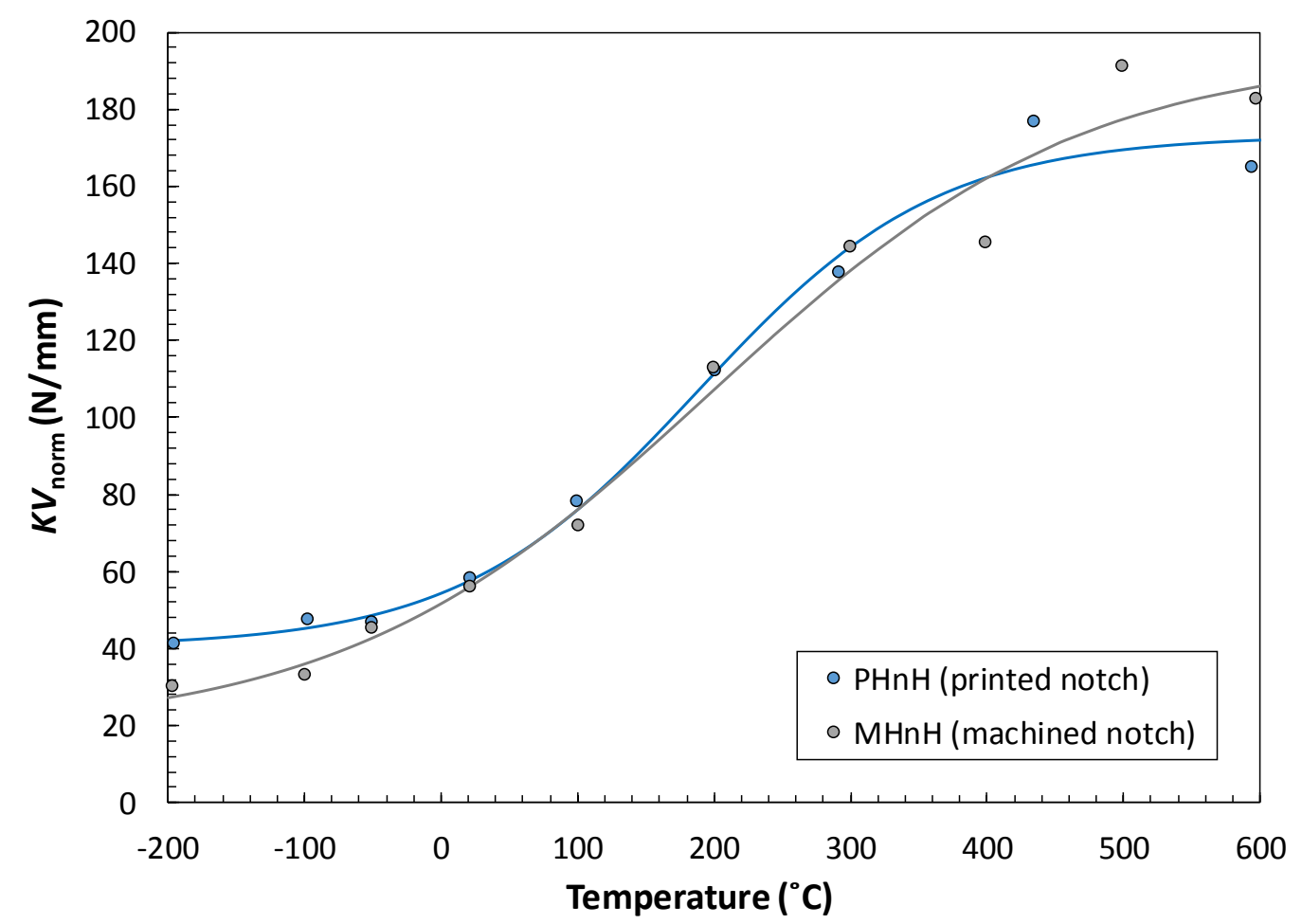

Figure 22 - Comparison between printed and machined notches for non-HIPped, horizontal specimens in terms of normalized absorbed energy. 


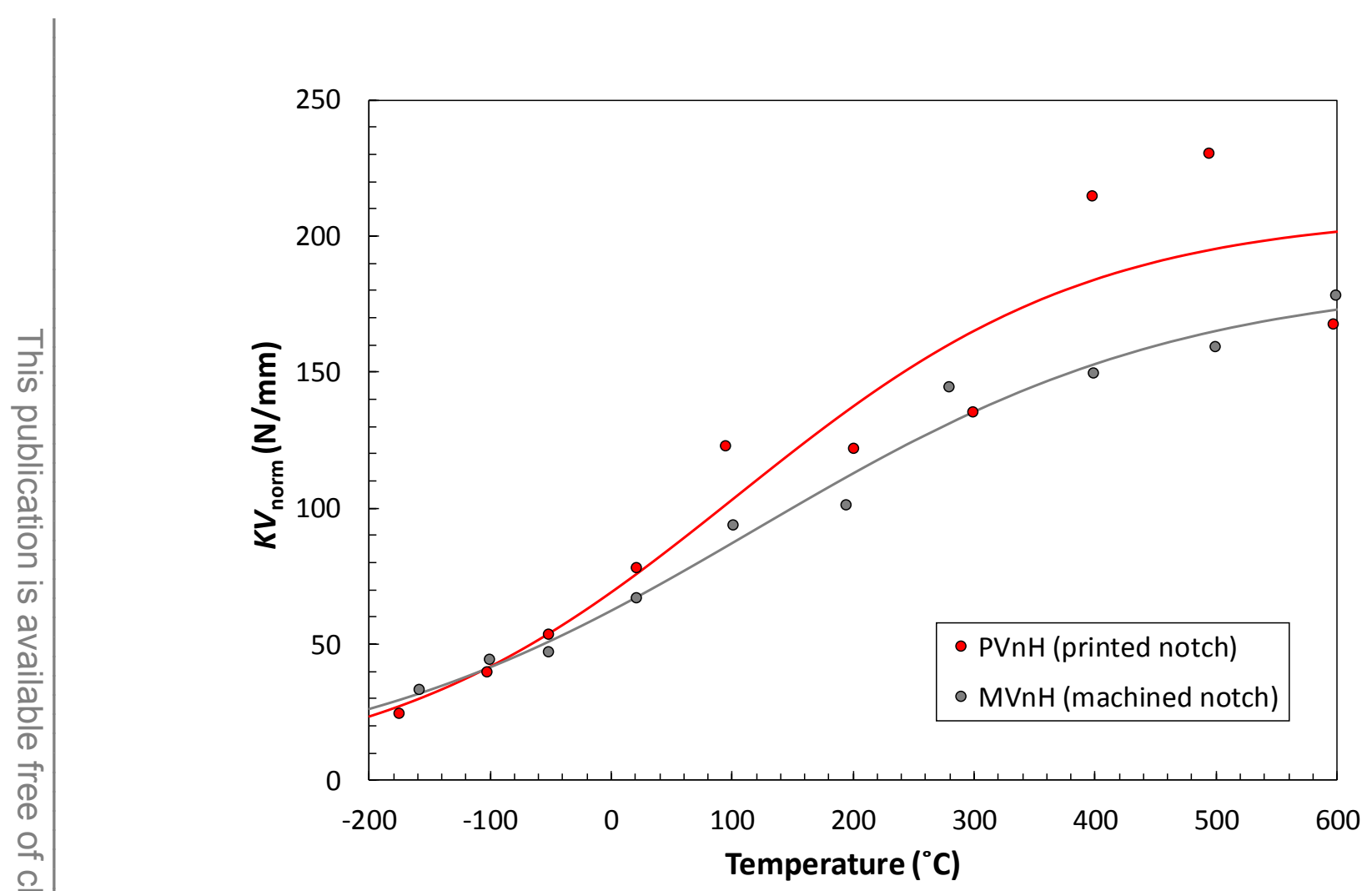

Figure 23 - Comparison between printed and machined notches for non-HIPped, vertical specimens in terms of normalized absorbed energy.

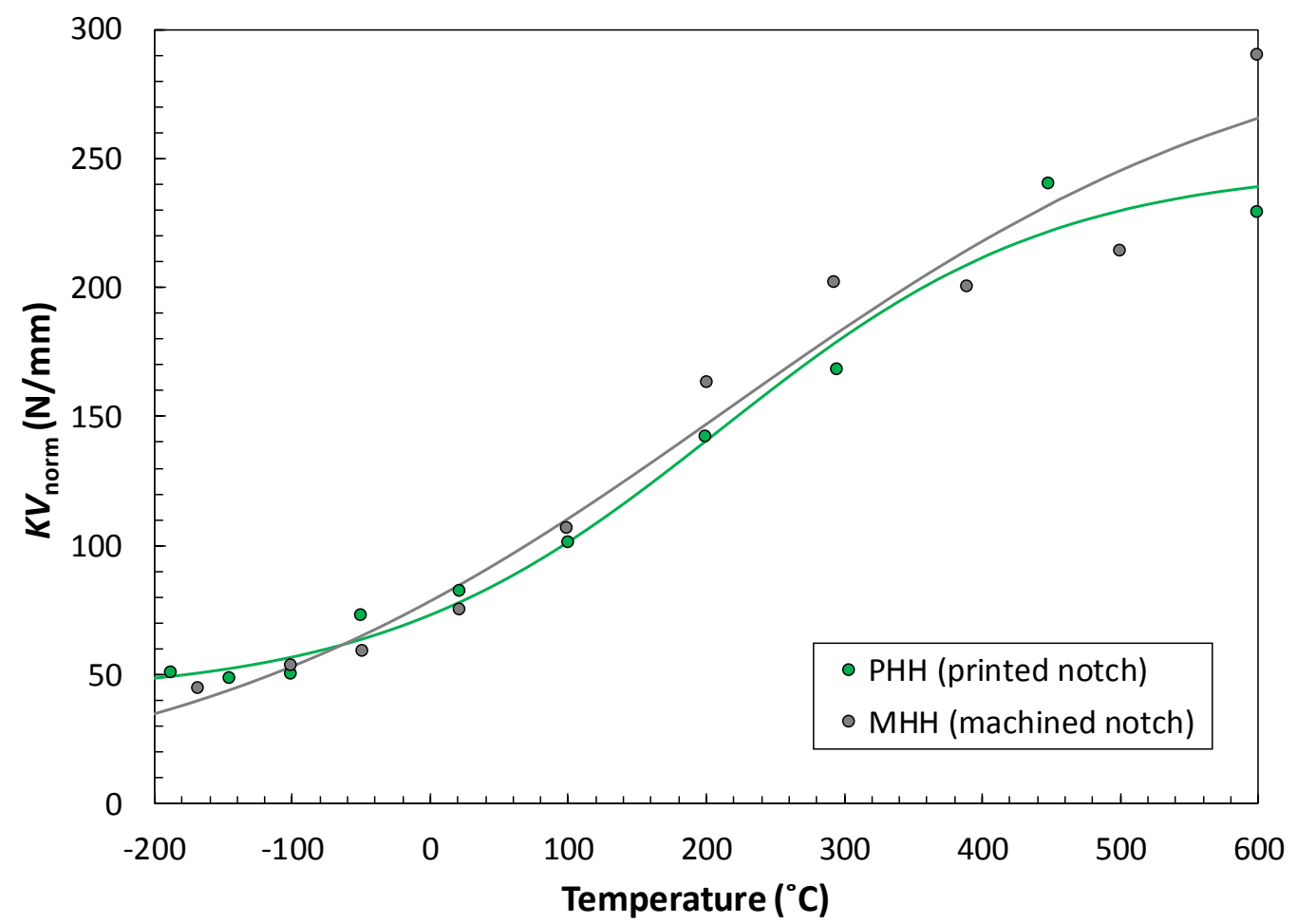

Figure 24 - Comparison between printed and machined notches for HIPped, horizontal specimens in terms of normalized absorbed energy. 


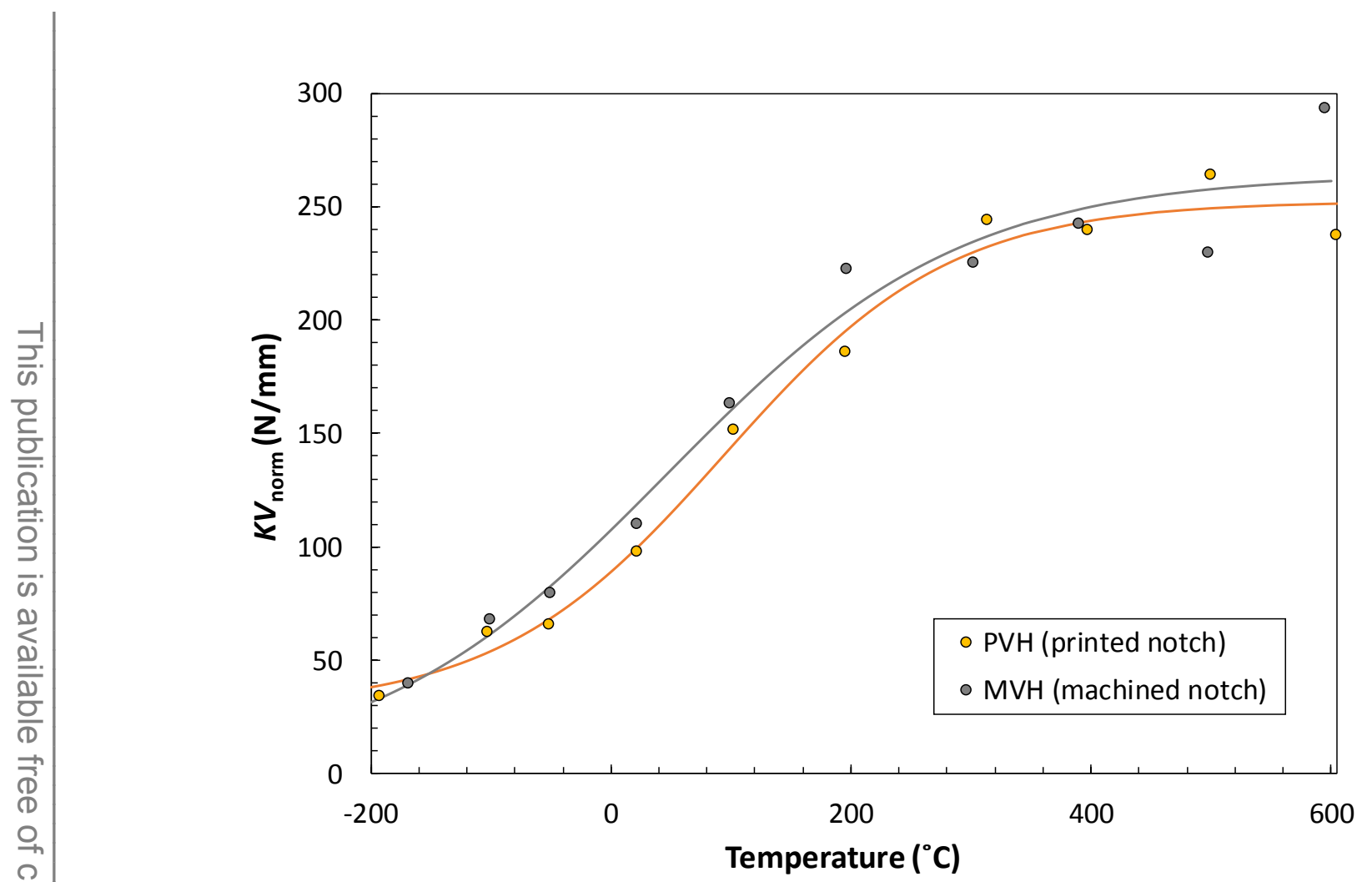

Figure 25 - Comparison between printed and machined notches for HIPped, vertical specimens in terms of normalized absorbed energy.

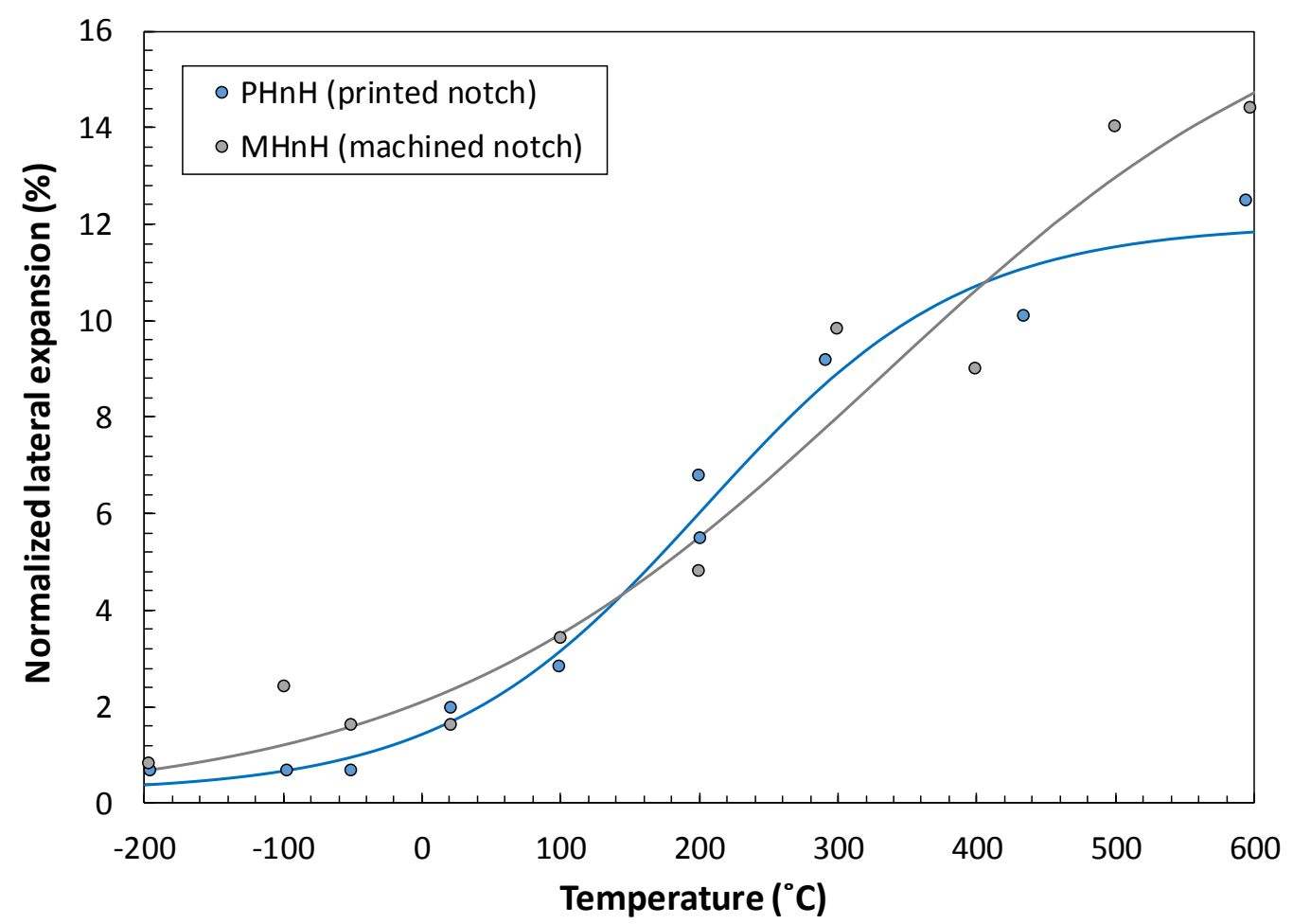

Figure 26 - Comparison between printed and machined notches for non-HIPped, horizontal specimens in terms of normalized lateral expansion. 


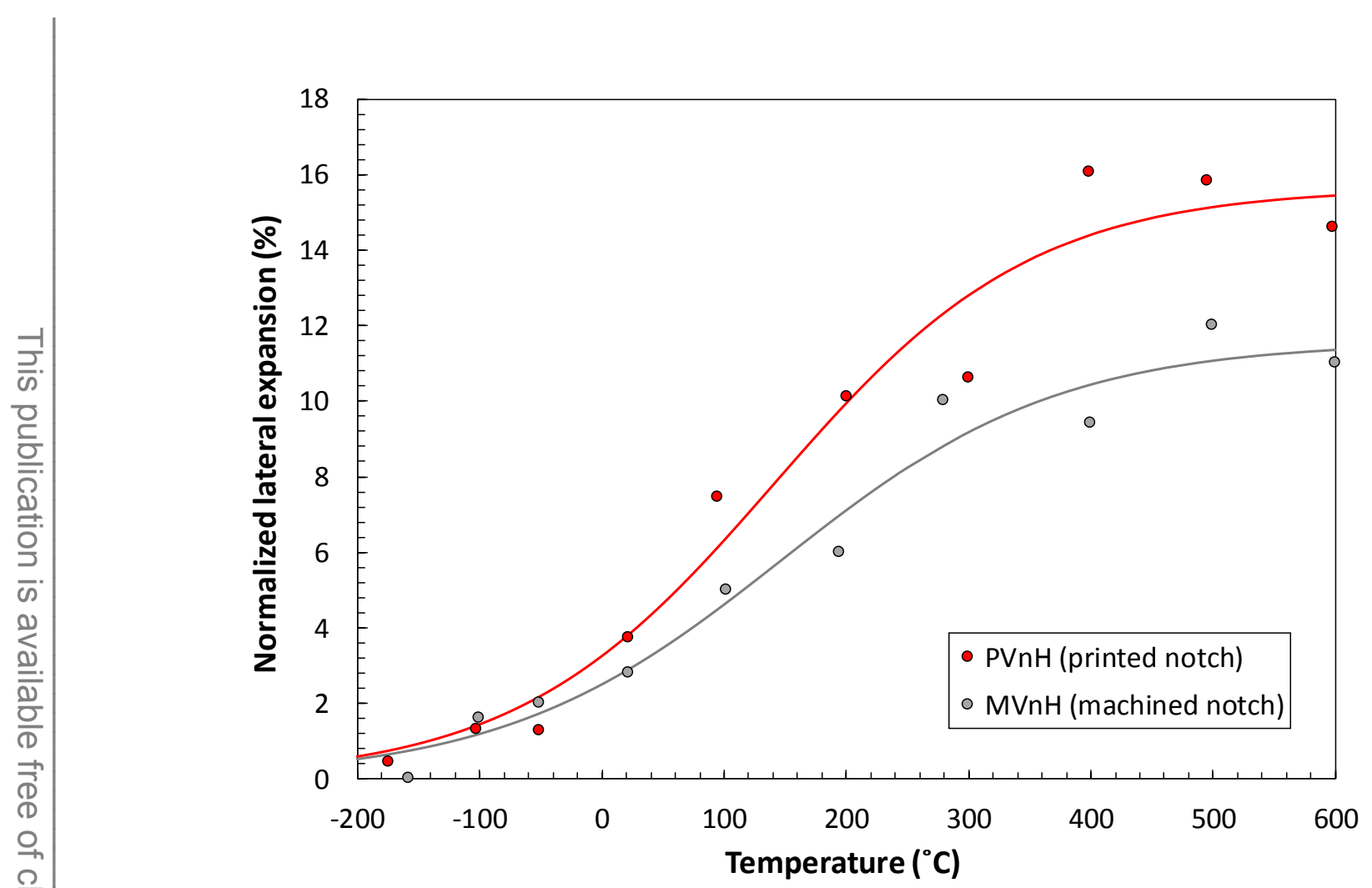

Figure 27 - Comparison between printed and machined notches for non-HIPped, vertical specimens in terms of normalized lateral expansion.

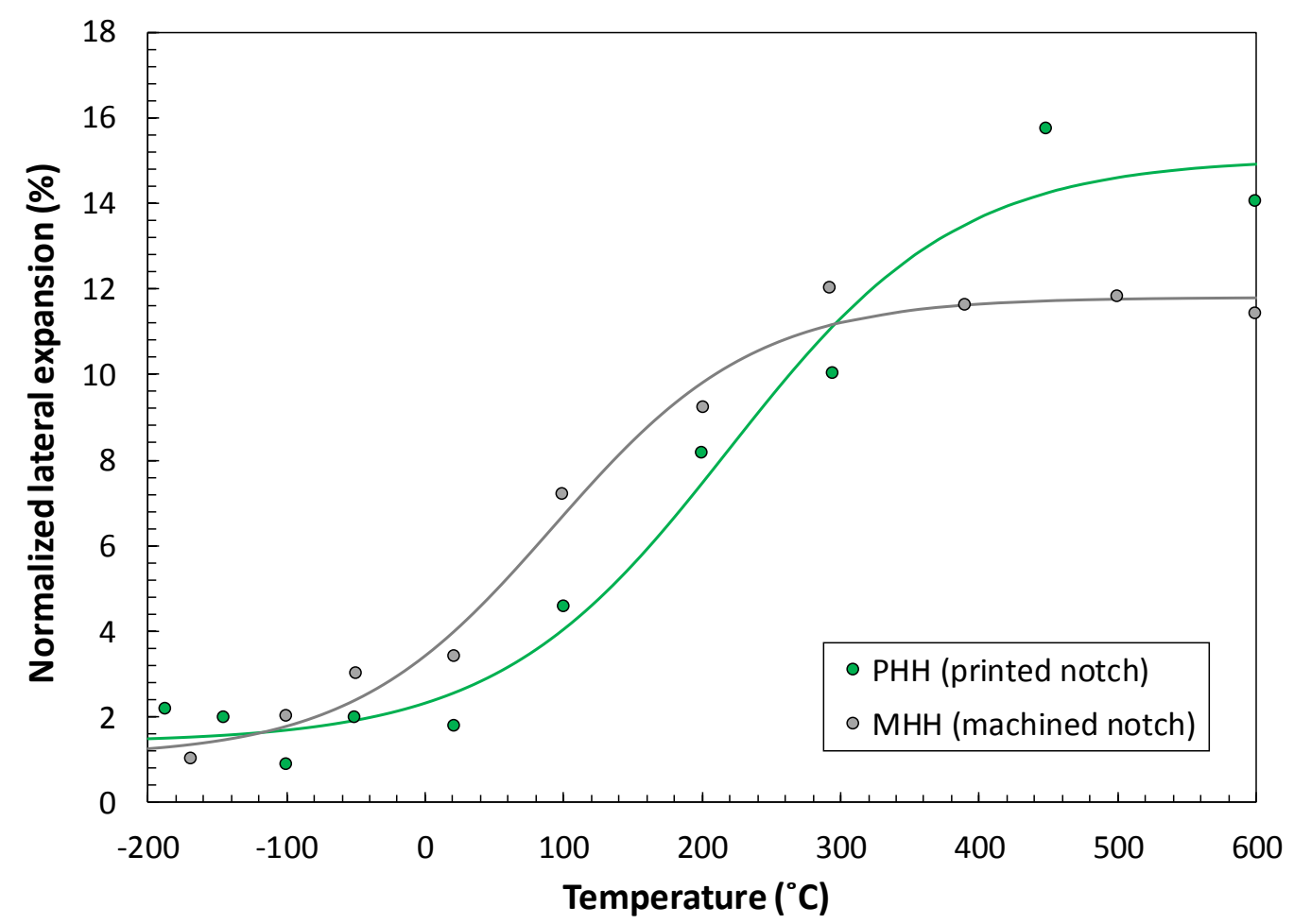

Figure 28 - Comparison between printed and machined notches for HIPped, horizontal specimens in terms of normalized lateral expansion. 


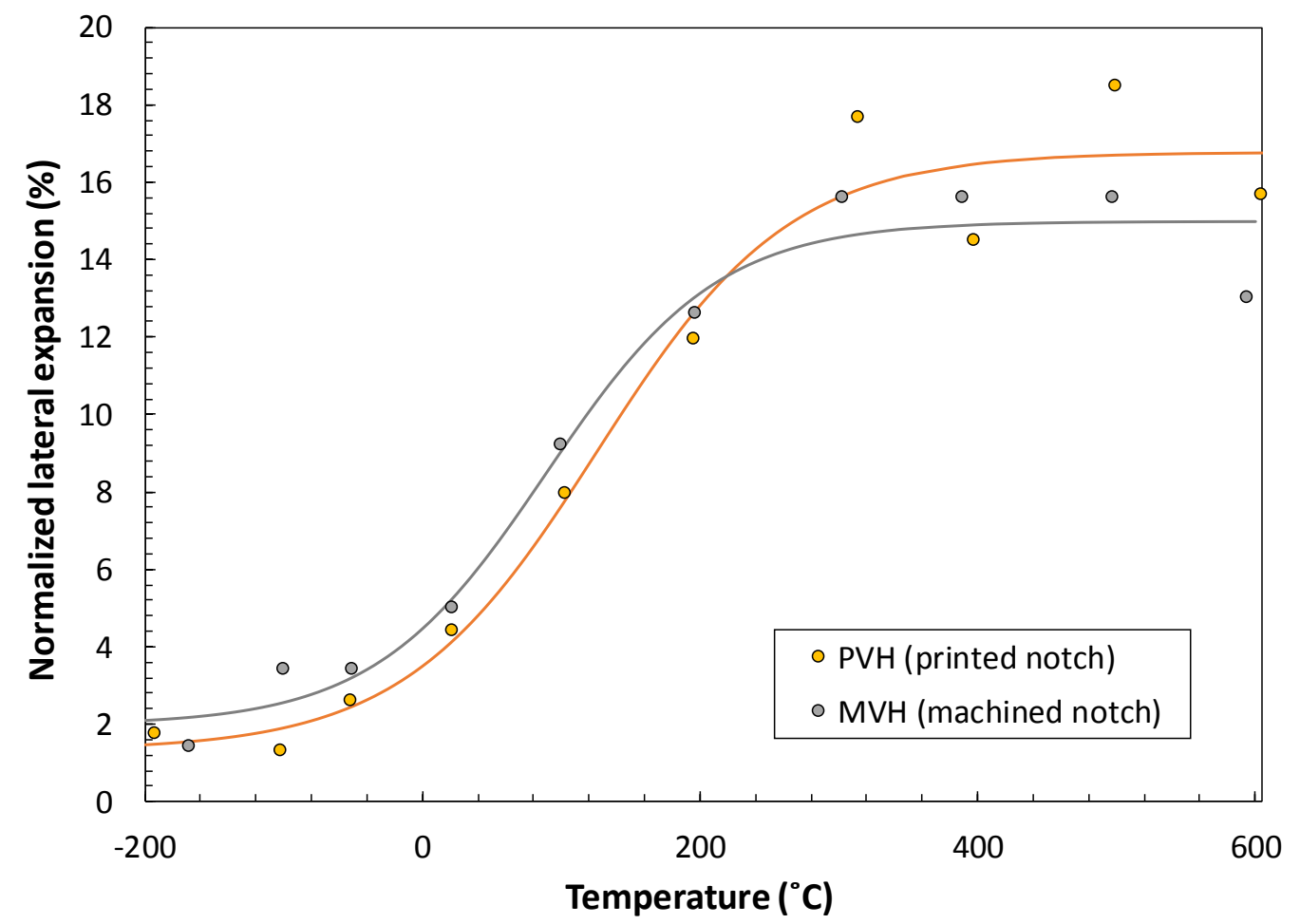

Figure 29 - Comparison between printed and machined notches for HIPped, vertical specimens in terms of normalized lateral expansion.

\subsection{AM vs. non-AM (wrought)}

The results we obtained from the combined baseline data set (B1-B2, specimens extracted from two wrought bars) were compared with the different AM data sets.

Normalized absorbed energy data and transition curves are compared in Figure 30 for non-HIPped AM conditions and in Figure 31 for HIPped AM conditions.

Our results indicate that the impact toughness of AM specimens in non-HIPped condition is similar to that of non-AM (wrought) specimens up to $200{ }^{\circ} \mathrm{C}$. In the upper transition and upper shelf regions up to $600{ }^{\circ} \mathrm{C}$, the wrought material exhibits better impact toughness properties.

After HIPping, the AM material shows better impact toughness than the wrought material (particularly in the vertical direction) up to $200{ }^{\circ} \mathrm{C}$, and similar behavior between $200{ }^{\circ} \mathrm{C}$ and $600{ }^{\circ} \mathrm{C}$.

Other factors which should be taken into account, when comparing test results between $\mathrm{AM}$ and non-AM specimens, are the following.

1. Chemistry differences, and more specifically oxygen and hydrogen contents (Table 1). An increase in both $\mathrm{O}$ content $(0.18 \%$ for the baseline conditions versus $0.14 \%$ for the AM conditions) and $\mathrm{H}$ content (30 ppm vs. $10 \mathrm{ppm}$ ) is generally expected to lower the toughness of Ti-6Al-4V $[9,10]$. However, our results do not confirm this expected trend. 
2. Microstructure differences: baseline specimens have a mill-annealed microstructure, whereas AM specimens exhibit an acicular microstructure. This acicular (or martensitic alpha) microstructure tends to improve fracture toughness [11], and could be a contributing factor for the results obtained. More work is however needed to ascertain the effect of microstructure on impact toughness.

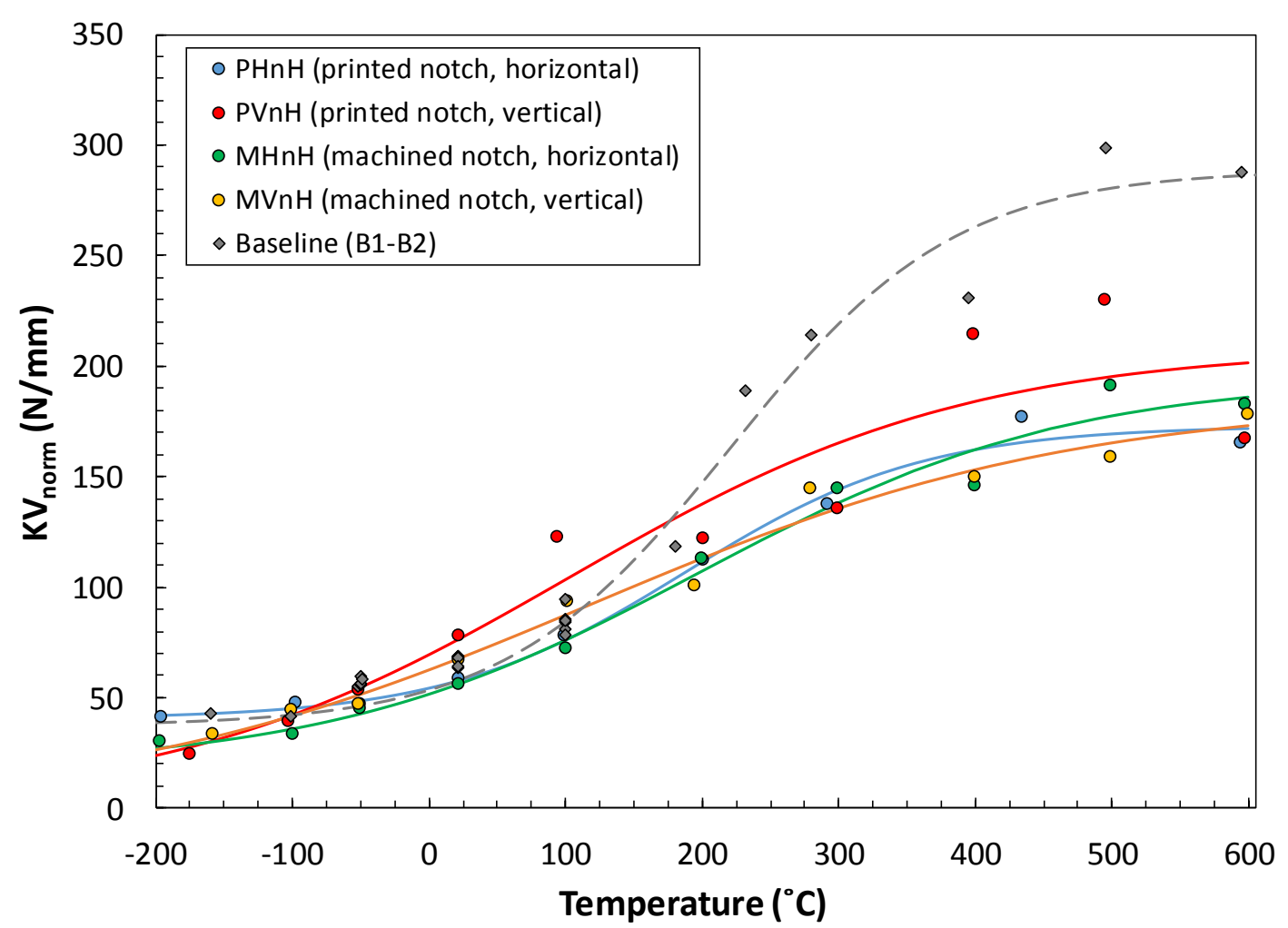

Figure 30 - Normalized absorbed energy for AM non-HIPped conditions and non-AM conditions. 


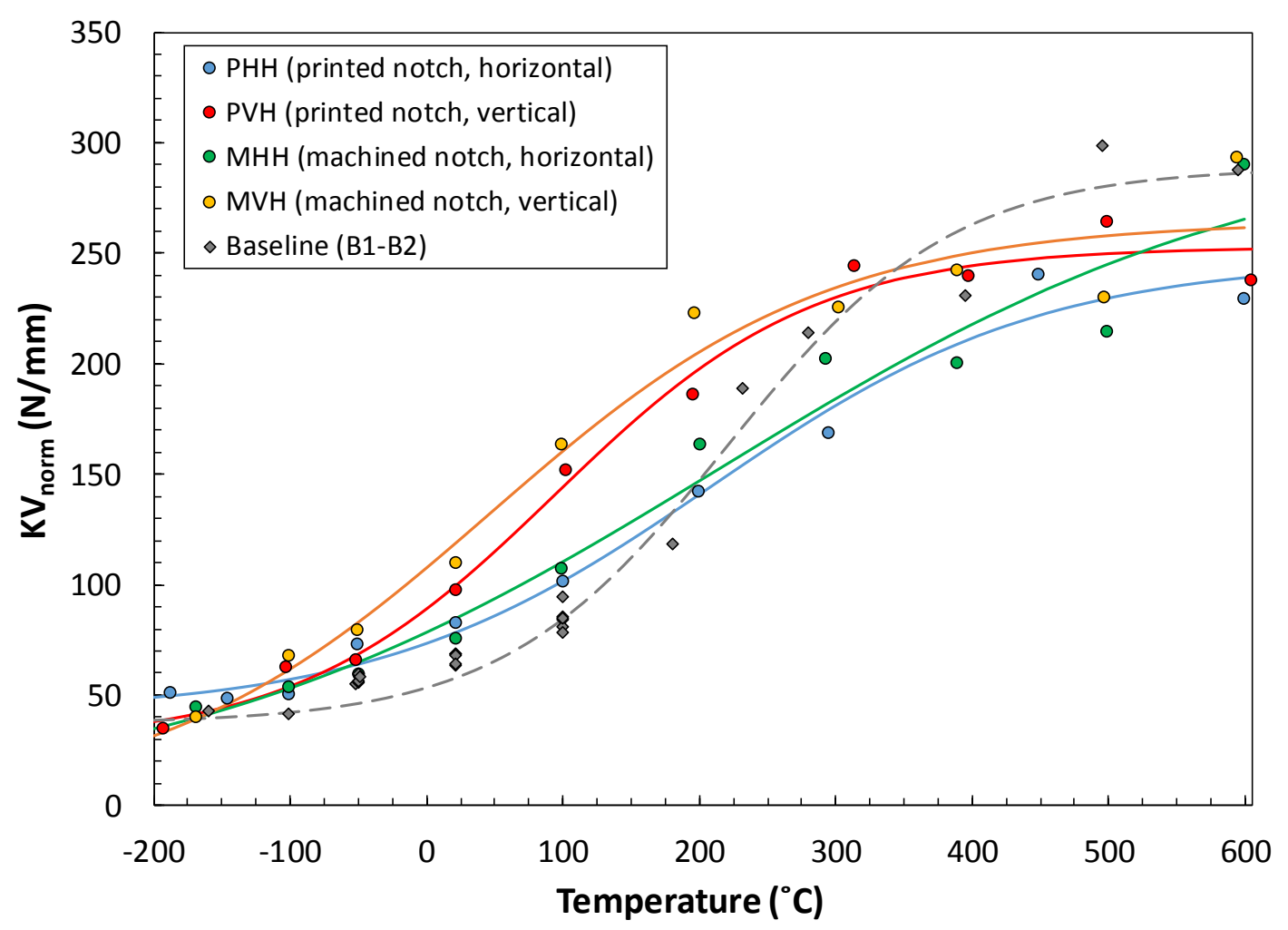

Figure 31 -Normalized absorbed energy for AM HIPped conditions and non-AM conditions.

\subsection{Characteristic instrumented forces}

The values of force at general yield and maximum force obtained for the different conditions investigated are reported in Table 13. It can be noted that several values are missing, corresponding to tests when the acquisition system failed to trigger or triggered incorrectly.

Forces at general yield $\left(F_{g y}\right)$ and maximum forces $\left(F_{m}\right)$ from AM specimens are compared to baseline data in Figure 32 and Figure 33 for printed notches, and Figure 34 and Figure 35 for machined notches. Our results indicate a substantial equivalence of forces at general yield and maximum forces, and hence dynamic tensile properties, between AM and non-AM specimens, irrespective of the notch configuration. 
Table 13 - Characteristic values of force measured from the instrumented Charpy tests performed.

\begin{tabular}{|c|c|c|c|c|c|c|c|}
\hline $\begin{array}{l}\text { Material } \\
\text { condition }\end{array}$ & $\begin{array}{c}\mathbf{T} \\
\left({ }^{\circ} \mathbf{C}\right)\end{array}$ & $\begin{array}{c}F_{g y} \\
(\mathbf{k N})\end{array}$ & $\begin{array}{c}F_{m} \\
(\mathbf{k N})\end{array}$ & $\begin{array}{l}\text { Material } \\
\text { condition }\end{array}$ & $\begin{array}{c}\mathbf{T} \\
\left({ }^{\circ} \mathbf{C}\right)\end{array}$ & $\begin{array}{c}F_{g y} \\
(\mathbf{k N})\end{array}$ & $\begin{array}{c}F_{m} \\
(\mathbf{k N})\end{array}$ \\
\hline \multirow{15}{*}{ B1 } & -160 & 6.09 & 8.18 & \multirow{15}{*}{ B2 } & -51 & 5.01 & 6.71 \\
\hline & -101 & 5.98 & 7.70 & & -52 & 4.95 & 6.66 \\
\hline & -50 & 5.36 & 7.13 & & -49 & 5.39 & 6.59 \\
\hline & 21 & 4.66 & 6.61 & & -50 & 4.86 & 6.67 \\
\hline & 100 & 5.00 & 6.13 & & -50 & 5.30 & 6.67 \\
\hline & 180 & 4.85 & 5.86 & & 21 & 4.55 & 6.01 \\
\hline & 232 & 5.20 & 6.28 & & 21 & 4.89 & 5.99 \\
\hline & 280 & 4.71 & 5.64 & & 21 & 4.63 & 6.02 \\
\hline & 395 & 4.29 & 5.21 & & 21 & 5.12 & 6.15 \\
\hline & 495 & 3.86 & 4.86 & & 21 & 4.77 & 6.09 \\
\hline & 595 & 3.40 & 4.31 & & 100 & 4.43 & 5.59 \\
\hline & \multirow[t]{4}{*}{700} & \multirow[t]{4}{*}{2.89} & \multirow[t]{4}{*}{3.73} & & 100 & 3.97 & 5.62 \\
\hline & & & & & 100 & 4.52 & 5.69 \\
\hline & & & & & 100 & 4.43 & 5.71 \\
\hline & & & & & 100 & 4.39 & 5.67 \\
\hline \multirow{10}{*}{ PHnH } & -195 & 5.35 & 6.79 & \multirow{10}{*}{ PVnH } & -174 & 3.88 & 5.48 \\
\hline & -97 & 4.98 & 6.47 & & -102 & 4.17 & 5.65 \\
\hline & -50 & 4.56 & 6.11 & & -51 & 3.99 & 5.93 \\
\hline & 22 & - & - & & 22 & 4.12 & 5.49 \\
\hline & 100 & - & - & & 95 & - & - \\
\hline & 200 & 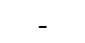 & - & & 201 & 3.59 & 4.51 \\
\hline & 201 & 3.73 & 5.04 & & 300 & 3.23 & 4.57 \\
\hline & 292 & - & - & & 399 & 3.55 & 4.30 \\
\hline & 435 & 4.51 & 6.28 & & 495 & 2.88 & 3.81 \\
\hline & 595 & - & - & & 598 & 2.76 & 3.34 \\
\hline \multirow{10}{*}{ PHH } & -187 & 5.50 & 7.01 & \multirow{10}{*}{ PVH } & -192 & - & - \\
\hline & -145 & 5.25 & 7.02 & & -102 & 4.41 & 6.24 \\
\hline & -100 & 4.41 & 6.51 & & -51 & 4.37 & 5.87 \\
\hline & -50 & 4.67 & 6.24 & & 22 & 4.12 & 5.26 \\
\hline & 22 & 4.47 & 5.44 & & 103 & 4.31 & 5.09 \\
\hline & 101 & 3.65 & 5.13 & & 196 & 3.97 & 4.83 \\
\hline & 200 & 3.64 & 4.78 & & 314 & - & - \\
\hline & 295 & 3.65 & 4.64 & & 398 & 3.62 & 4.62 \\
\hline & 449 & 3.38 & 4.73 & & 500 & 3.13 & 3.97 \\
\hline & 600 & 2.92 & 3.91 & & 605 & 2.73 & 3.32 \\
\hline \multirow{10}{*}{ MHnH } & -196 & 6.17 & 7.12 & \multirow{10}{*}{ MVnH } & -158 & 5.39 & 7.26 \\
\hline & -99 & 4.60 & 7.10 & & -100 & 5.62 & 7.49 \\
\hline & -50 & 5.90 & 6.69 & & -51 & 4.63 & 6.80 \\
\hline & 22 & 4.87 & 6.31 & & 22 & 4.38 & 6.64 \\
\hline & 101 & 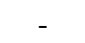 & - & & 102 & - & - \\
\hline & 200 & - & 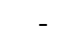 & & 195 & - & - \\
\hline & 300 & 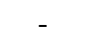 & - & & 280 & - & - \\
\hline & 400 & 5.13 & 6.23 & & 400 & 4.08 & 5.21 \\
\hline & 500 & 4.91 & 6.15 & & 500 & 3.87 & 4.80 \\
\hline & 598 & 4.67 & 5.39 & & 600 & 3.37 & 4.46 \\
\hline \multirow{10}{*}{ МHН } & -168 & 5.89 & 7.88 & \multirow{10}{*}{ MVH } & -168 & 5.70 & 7.59 \\
\hline & -100 & 4.85 & 7.27 & & -100 & 6.23 & 7.18 \\
\hline & -49 & 5.71 & 7.21 & & -50 & 5.54 & 7.36 \\
\hline & 22 & 4.50 & 6.69 & & 22 & 5.09 & 6.73 \\
\hline & 100 & 5.10 & 6.14 & & 100 & 5.20 & 6.25 \\
\hline & 201 & - & & & 197 & 5.06 & 6.00 \\
\hline & 293 & - & & & 303 & - & - \\
\hline & 390 & 4.70 & 5.68 & & 390 & 4.72 & 5.74 \\
\hline & 500 & 2.77 & 3.43 & & 498 & 4.10 & 4.93 \\
\hline & 600 & 3.60 & 4.80 & & 595 & 3.72 & 4.87 \\
\hline
\end{tabular}




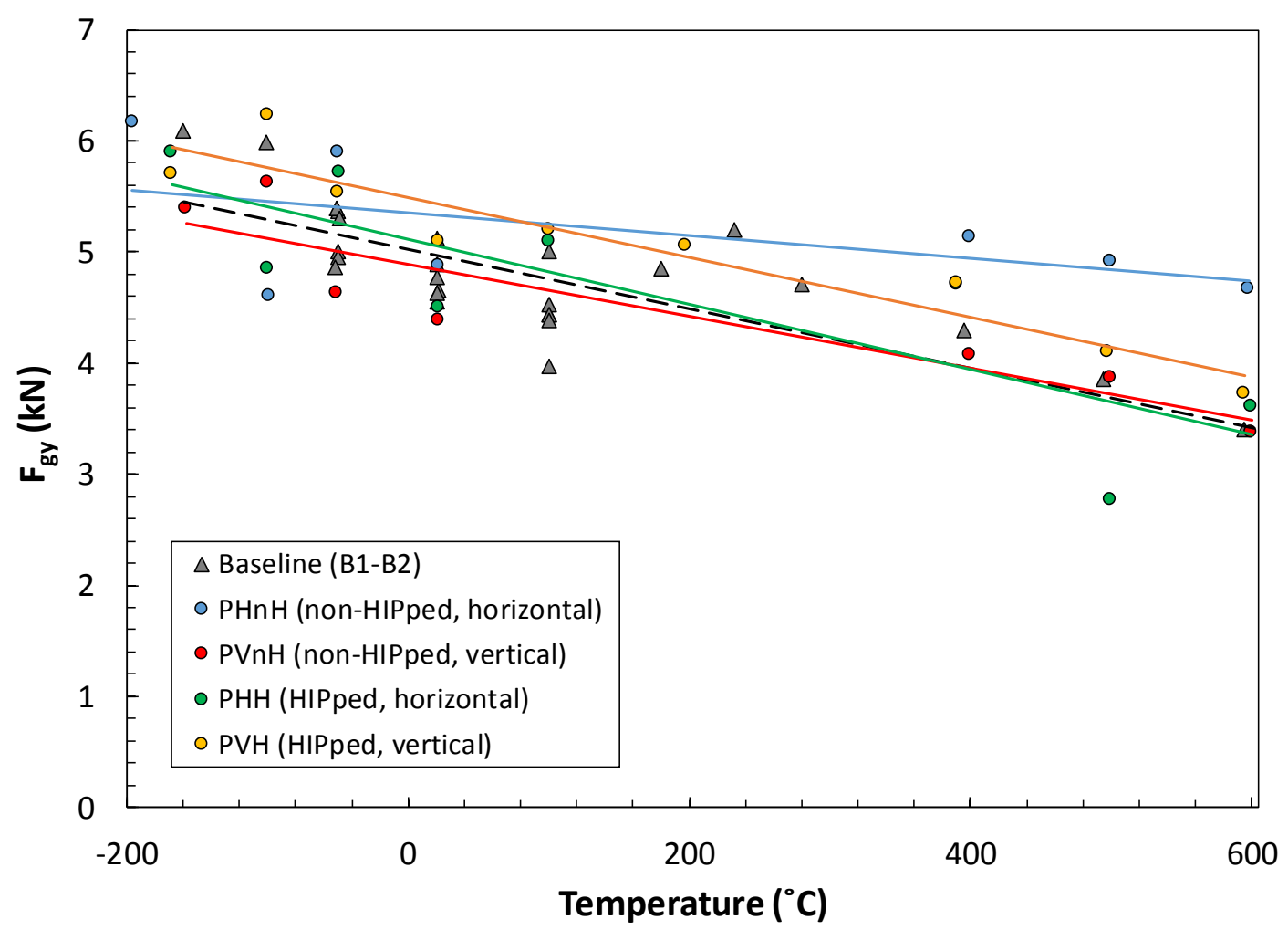

Figure 32 - Forces at general yield from baseline and AM (printed notch) specimens.

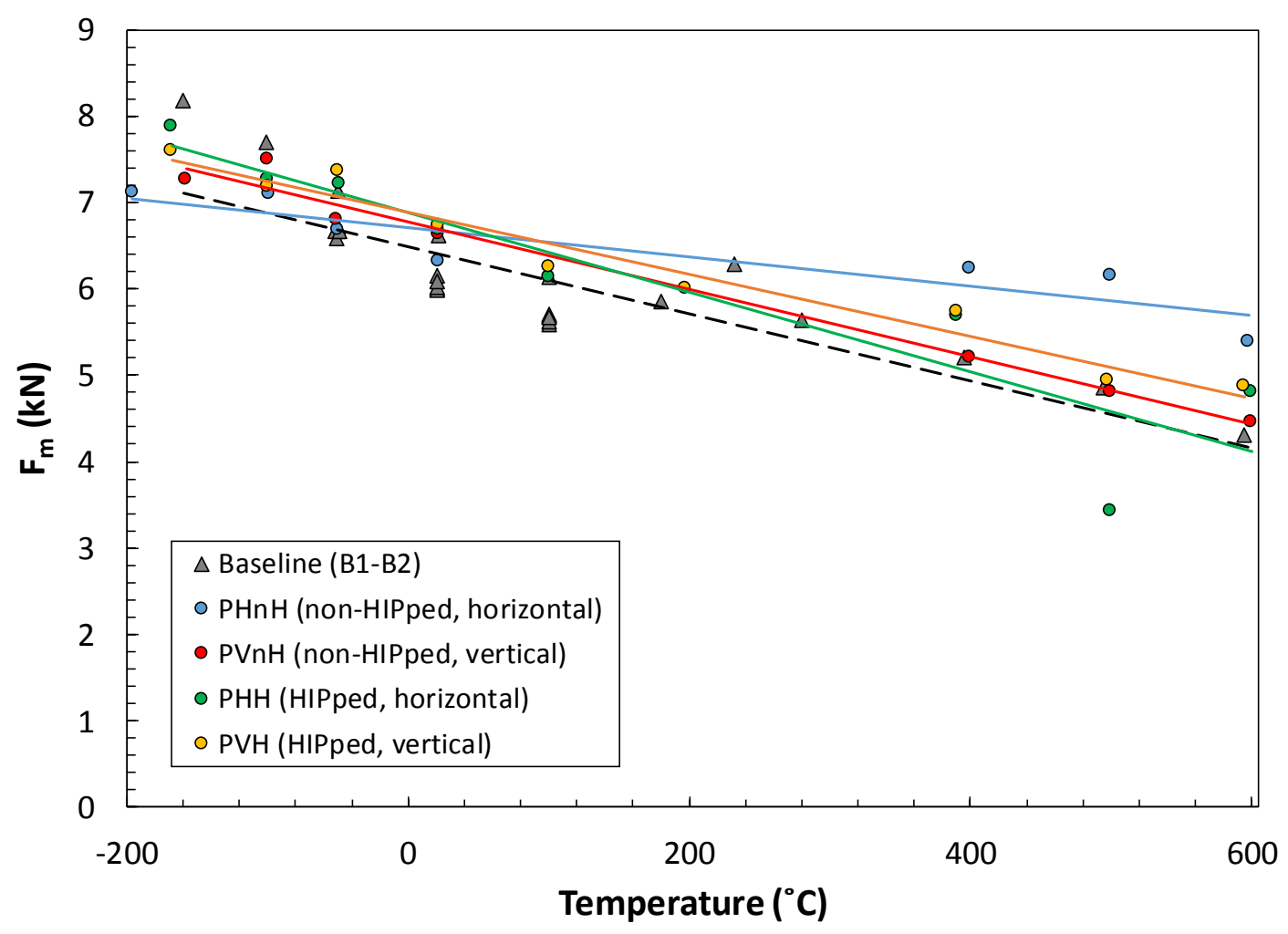

Figure 33 - Maximum forces from baseline and AM (printed notch) specimens. 


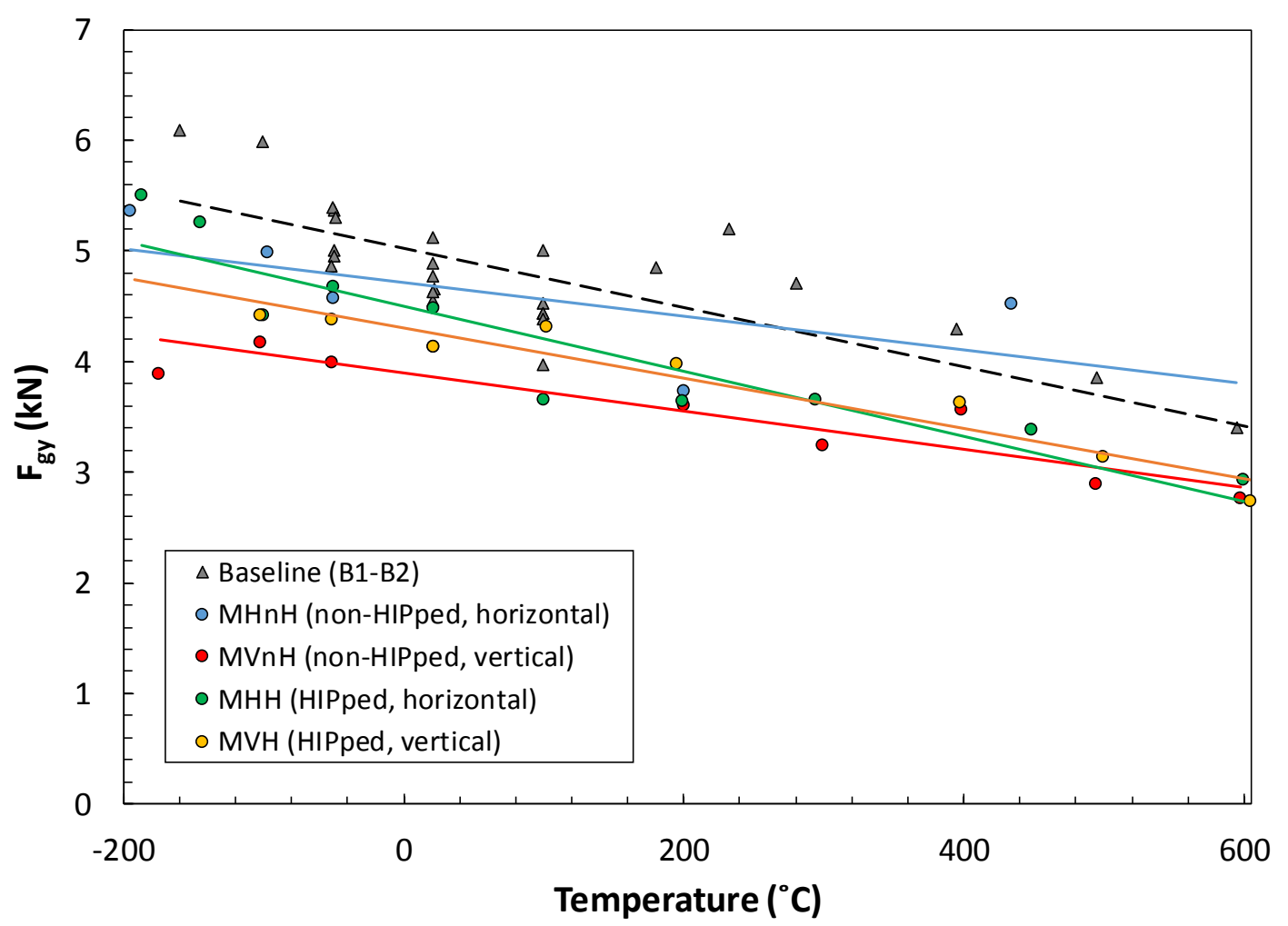

Figure 34 - Forces at general yield from baseline and AM (machined notch) specimens.

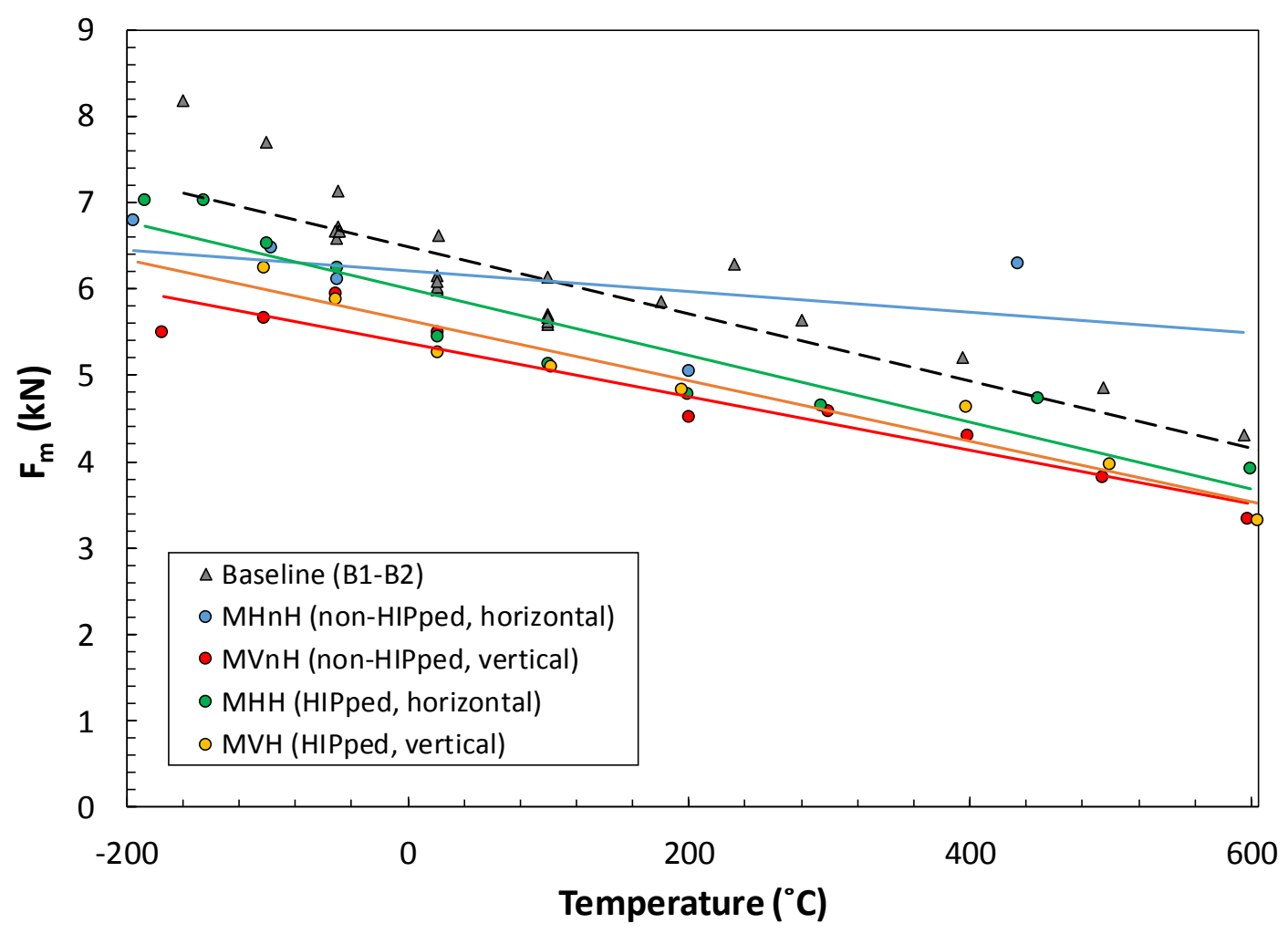

Figure 35 - Maximum forces from baseline and AM (machined notch) specimens. 


\section{Conclusions}

More than 100 instrumented impact tests on miniaturized Charpy specimens were performed at NIST in Boulder for the characterization of the impact toughness of Ti-6Al-4V in different conditions (wrought and additively manufactured). The effect of various parameters was also investigated (specimen orientation, hot isostatic pressing, printed vs. machined notches).

The main conclusions that can be drawn from this investigation are presented below.

- For additively-manufactured specimens, we observed that the material is more resistant to cracks growing in the plane perpendicular to the build direction (vertical orientation) than in the plane containing the build direction (horizontal orientation). Orientation effects are more significant for non-HIPped specimens and lower temperatures (below $200{ }^{\circ} \mathrm{C}$ ).

- Hot Isostatic Pressing (HIPping) reduces porosity and increases the density of the AM material, and consequently significantly improves impact toughness. The increase of normalized absorbed energy at $21{ }^{\circ} \mathrm{C}$ and $350{ }^{\circ} \mathrm{C}$ ranges between $30 \%$ and $70 \%$, presumably as a consequence of the reduction in available fracture initiation sites.

- The configuration of the Charpy specimen notch (printed or machined) does not have a significant effect on the impact toughness of AM specimens, despite the ruggedness and asperities observed in printed notches.

- Below $200{ }^{\circ} \mathrm{C}$, the impact toughness of AM specimens is similar to that of wrought material in the non-HIPped condition, while the wrought material performs better at higher temperatures. After HIPping, AM specimens exhibit better impact toughness than wrought material below $200{ }^{\circ} \mathrm{C}$, and the properties appear similar between $200{ }^{\circ} \mathrm{C}$ and $600{ }^{\circ} \mathrm{C}$.

- Based on instrumented forces at general yield and maximum forces measured from instrumented impact tests, the dynamic tensile properties of additively-manufactured and wrought specimens appear similar, irrespective of notch configuration, specimen orientation, and post-manufacturing heat treatment (HIPped or non-HIPped).

\section{Acknowledgments}

Sincere thanks to Victoria "Torie" Duke, for her kind assistance in performing instrumented impact tests on baseline Ti-6Al-4V.

\section{References}

[1] Arcam EBM System, “Ti6Al4V Titanium Alloy," http://www.arcam.com/wpcontent/uploads/Arcam-Ti6Al4V-Titanium-Alloy.pdf (retrieved 9/2/2016). 
[2] E. Lucon, C. N. McCowan, and R. L. Santoyo, "Impact Characterization of 4340 and T200 Steels by Means of Standard, Sub-Size and Miniaturized Charpy Specimens," NIST Technical Note 1858, February 2015.

[3] E. Lucon, C. N. McCowan, and R. L. Santoyo, "Impact Characterization of Line Pipe Steels by Means of Standard, Sub-Size and Miniaturized Charpy Specimens," NIST Technical Note 1865, February 2015.

[4] E. Lucon, C. McCowan, and R. Santoyo, “Overview of NIST Activities on Sub-Size and Miniaturized Charpy Specimens: Correlations with Full-Size Specimens and Verification Specimens for SmallScale Pendulum Machines," Journal of Pressure Vessel Technology, Vol. 138, No. 3, Feb 2016.

[5] W. Oldfield, "Fitting Curves to Toughness Data," Journal of Testing and Evaluation, JTEVA, Vol. 7, No. 6, Nov 1979, pp. 326-333.

[6] W. L. Server, "General Yielding of Charpy V-Notch and Precracked Charpy Specimens," Journal of Engineering Materials and Technology, Vol. 100, No. 2, April 1978, pp. 183-188.

[7] E. Lucon, "Estimating dynamic ultimate tensile strength from instrumented Charpy data," Materials \& Design, Vol. 97, May 2016, pp. 437-443.

[8] H. V. Atkinson and S. Davies, "Fundamental aspects of hot isostatic pressing: An overview," Metallurgical and Materials Transactions A, Vol. 31, No. 12, Dec 2000, pp. 2981-3000.

[9] R. R. Ferguson and R. G. Berryman, "Fracture Mechanics Evaluation of B-1 Materials," Report AFML-TR-76-137, Vol. 1, Rockwell International, Los Angeles, 1976.

[10] S. D. Henry, G. M. Davidson, S. R. Lampman, F. Reidenbach, R. L. Boring, and W. W. Scott, Jr., "Titanium Alloys Fatigue and Fracture," in Fatigue Data Book: Light Structural Alloys, ASM International, 1995, pp. 183-204.

[11] F. H. Froes, "Mechanical Properties and Testing of Titanium Alloys," in Titanium - Physical Metallurgy Processing and Applications, ASM International, 2015, pp. 113-140. 